\title{
Dramatic decline and limited recovery of a green crab (Carcinus maenas) population in the Minas Basin, Canada after the summer of 2013
}

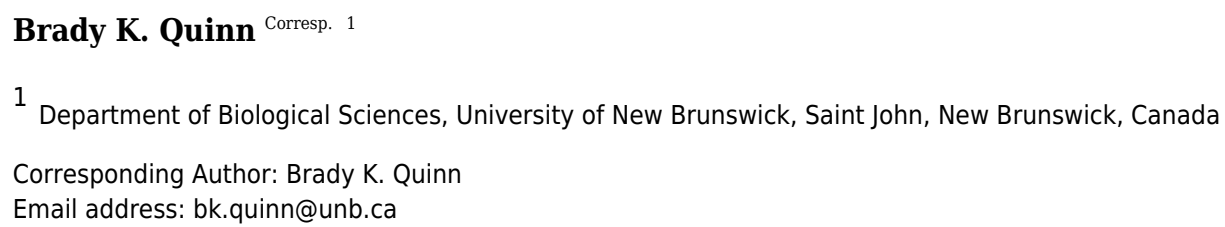

This paper reports the results of a ten-year monitoring program of an Atlantic Canadian population of green crabs, Carcinus maenas, in the Minas Basin of the Bay of Fundy. Intertidal densities, sex and reproductive ratios, juvenile recruitment, subtidal catch-perunit-effort (CPUE), and sizes of crabs in this population were recorded from 2008 to 2017. In 2013 intertidal densities, mean crab sizes, subtidal CPUE, and proportions of crabs mature and reproducing all dramatically decreased to all-time lows, and large crabs virtually disappeared from the population. From 2014 to 2017 the population partially recovered but remained in an altered state. Potential causes of interannual changes to this population were investigated by correlating intertidal densities to 257 monthly environmental variables and performing stepwise multiple regression analyses. Crab densities in a given year were best explained by potential settlement during the summer and the maximum sea-surface temperature during March of the same year. However, potential roles of other factors (e.g., autumn winds, summer temperatures, North Atlantic Oscillation index) could not be ruled out. Changes in abundances of other species in the region, particularly predators and prey of green crabs, have also been observed and present possible alternative causative agents that should be investigated. Populations of other marine species in the Gulf of Maine-Bay of Fundy region within which the Minas Basin is situated have also been reported to have undergone dramatic changes in and after 2013, suggesting the occurrence of some oceanographic event or regime shift in the region. Declines to the monitored crab population in this study may have resulted from this same 2013 event. These observations have implications for recruitment to marine populations in this region. 
1 Dramatic decline and limited recovery of a green crab (Carcinus maenas) population in the

2

3

4

5 Department of Biological Sciences, University of New Brunswick, 100 Tucker Park Road, Saint Minas Basin, Canada after the summer of 2013
6

7

8

9

10

11

12

13

14

15

16

17

18

19

20

21

22

23

2

17

18

19

20

John, NB, Canada E2L 4L5

*Corresponding author: bk.quinn@,unb.ca, 1-506-343-7676

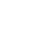

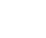

(1)

3

4

5


25

This paper reports the results of a ten-year monitoring program of an Atlantic Canadian population of green crabs, Carcinus maenas, in the Minas Basin of the Bay of Fundy. Intertidal densities, sex and reproductive ratios, juvenile recruitment, subtidal catch-per-unit-effort (CPUE), and sizes of crabs in this population were recorded from 2008 to 2017. In 2013 intertidal densities, mean crab sizes, subtidal CPUE, and proportions of crabs mature and reproducing all dramatically decreased to all-time lows, and large crabs virtually disappeared from the population. From 2014 to 2017 the population partially recovered but remained in an altered state. Potential causes of interannual changes to this population were investigated by correlating intertidal densities to 257 monthly environmental variables and performing stepwise multiple regression analyses. Crab densities in a given year were best explained by potential settlement during the summer and the maximum sea-surface temperature during March of the same year. However, potential roles of other factors (e.g., autumn winds, summer temperatures, North Atlantic Oscillation index) could not be ruled out. Changes in abundances of other species in the region, particularly predators and prey of green crabs, have also been observed and present possible alternative causative agents that should be investigated. Populations of other marine species in the Gulf of Maine-Bay of Fundy region within which the Minas Basin is situated have also been reported to have undergone dramatic changes in and after 2013, suggesting the occurrence of some oceanographic event or regime shift in the region. Declines to the monitored crab population in this study may have resulted from this same 2013 event. These observations have implications for recruitment to marine populations in this region. 


\section{Introduction:}

48 Detailed observations over time made on organisms of the same species in one or more selected

49

locations, constituting the same putative 'population(s)', is a staple of studies in marine biology and ecology in general (Bertness et al., 1992; Santos \& Simon, 1980; McGaw, Edgell, \& Kaiser, 2011; Palumbi \& Pinski, 2014). Such monitoring can provide essential information about the life history and demography of the species of interest (Hoskin et al., 2011), its interactions with other species in the same community (Seitz, Knick, \& Westphal, 2011), and abiotic or biotic factors influencing recruitment to its populations (Scrosati \& Ellrich, 2016). When observational periods coincide with particularly disruptive events, for example natural disasters (Sato \& Chiba, 2016), the introduction of new invasive species (Delaney et al., 2008), or climate-driven shifts in oceanographic regimes (Mills et al., 2013; Pinsky et al., 2013), the impacts of such events on the studied species can be illuminating. Changes to abundances and size or reproductive structure of species' populations following such events, as well as overall shifts in community specific composition, illustrate which ecological changes impact particular species and how (Ruth \& Berghahn, 1989; Palumbi \& Pinsky, 2014; Bertness et al., 1992). These observations provide information that can potentially be used to forecast longer-term impacts of such changes into the future, which is essential for management and conservation of marine species (Ruth \& Berghahn, 1989; Pinsky et al., 2013; Wahle \& Carloni, 2017).

When a non-native species is introduced to a new location its impacts on native biota can be substantial (e.g., Klassen \& Locke, 2007; Scalici \& Gherardi, 2007), so monitoring introductions and their impacts provides important ecological information. Once an introduced species establishes an invasive population, however, it takes on a distinct role within the invaded community and is essentially a part of the invaded ecology (e.g., Boudreau \& Hamilton, 2012). 
Invaders may, however, be more sensitive to environmental perturbations in their invasive range than are native biota because invaders, unlike native biota, do not have the same evolutionary history with environmental conditions in their invaded range as do natives (Grosholtz \& Ruiz, 2002; Kienzle, 2015; MacDonald et al., 2018). It is thus possible that ecological shifts potentially affecting an entire biological community may first impact an invasive species before having similar effects on native taxa. Monitoring invasive as well as native populations can thus potentially serve as an early warning system for changes to the community or its ecosystem. The Bay of Fundy is an inlet of the Gulf of Maine, located along the Atlantic coast of eastern North America, with extremely large tidal ranges (up to $16.8 \mathrm{~m}$ ) and distinct marine communities, particularly in the Minas Basin and Chignecto Bay portions of the upper Bay (Daborn \& Pennachetti, 1979; Parker, Westhead, \& Service, 2007). Marine communities within the Gulf of Maine-Bay of Fundy system are currently facing a number of sources of stress and change, including rapid warming of ocean waters (Mills et al., 2013; Pinsky et al., 2013) and introduction of several invasive species (Moore et al., 2014; Klassen \& Locke, 2007).

Particularly influential in recent years have been very warm summers, such as the 2012 'heat wave', and possible associated shifts in oceanographic circulation (Mills et al., 2013). Indeed, many species in this system demonstrated low abundances or recruitment in the year 2013 (e.g., Clements, 2016; Wahle \& Carloni, 2017; see also Discussion), signalling some major disruption in the system that bears further investigation. One invasive species that has become wellestablished within the Bay of Fundy is the European green shore crab, Carcinus maenas. This species reached the Bay of Fundy in the 1950s and became established and numerous within the upper bay (i.e. the Minas Basin) in the late 1990s (Klassen \& Locke, 2007). Green crabs are aggressive consumers of a wide range of prey species as predators and scavengers (Crothers, 
93 1968; Trussell, Ewanchuck, \& Bertness, 2003; Klassen \& Locke, 2007; Boudreau \& Hamilton,

94 2012) and compete with native species preying on similar food sources (Grosholz et al., 2000;

95 Haarr \& Rochette, 2012). This species thus plays significant roles within food webs of marine

96 communities it has invaded (Wong \& Dowd, 2015).

This paper describes the results of efforts to monitor an established invasive population

of green crabs (Fig. 1A) at Clarke Head, Nova Scotia (NS), Canada (Fig. 1B, C), within the Minas Basin of the upper Bay of Fundy (Fig. 1D). Green crabs first appeared at this site ca. 1999, and very quickly increased in abundance and almost completely displaced local rock crabs (Cancer irroratus) from intertidal environments at Clarke Head by 2002 (pers. obs. by author). A specific monitoring protocol was established by the author in 2008 and continued thereafter. Monitoring thus unfortunately missed the early years in which green crabs first appeared and became abundant at this location. However, this relatively new population within the area was still monitored to track its health and dynamics, as doing so is potentially useful to forecast impacts of changes to invader numbers on native biota, and to use it as a potential early warning system for changes to the marine ecology within the study area. During the monitoring period (2008-2017), a substantial change to the green crab population was observed beginning in 2013 and persisting to 2017. Within the present paper, the characteristics of the crab population before, during, and after this change are examined, and environmental changes potentially responsible are compared with changes in the crab population. Observations by recreational fishers and locals within the study area of biotic changes to crab bycatch and potential predators and prey of green crabs are also considered as a form of Local Ecological Knowledge (LEK; Cosham, Beazley, \& McCarthy, 2016) providing further avenues for research into causes of crab population changes. Findings for green crabs in the present study are also related to concurrent 
116 changes in the study region from 2013 onwards reported for other species and their potential

117 impacts.

118

119 Materials and methods

120 Study site and background:

121 This study was carried out along the intertidal and subtidal zones off of Clarke Head, a point of

122 land near Parrsboro, NS, Canada, tipped by a small cove surrounded by cliffs of sedimentary

123 rock (Fig. 1B, C). Clarke Head is located on the north shore of the Minas Basin, an inlet of the 124 upper Bay of Fundy (Fig. 1D). The upper intertidal zone at Clarke Head consists of a steeply

125 sloping gravel beach (Fig. 1B, C). The middle intertidal is a relatively flat area composed mainly

126 of sand or a mud-sand mix, interrupted by a series of rocky reefs of the same composition as the

127 surrounding cliffs and covered primarily with rockweed, Ascophyllum nodosum (Fig. 1B, C). A

128 previous study (Quinn, 2016) reported observations at the boundary between the upper and

129 middle intertidal zones at this location. A large middle intertidal mud flat is located to the north

130 of this area, just outside of the cove (Fig. 1C), and receives considerable freshwater input via a

131 stream called Swan Creek. The lower intertidal off of Clarke Head is defined by a large series of

132 gravel and sand bars to the south and north (Fig. 1B, C), in places bearing large aggregations of

133 barnacles (Semibalanus balanoides) and blue mussels (Mytilus sp.). Oceanic circulation within

134 the cove generally runs from southeast to northwest on flood tides and reverses on ebb tides.

135 Extremely low intertidal to high subtidal areas off of Clarke Head are also occasionally exposed

136 on spring tides, and consist of alternating sandy flats and rocky (cobble) ridges bearing seaweeds

137 such as Irish moss (Chondrus crispus), sea lettuce (Ulva sp.), and dulse (Palmaria palmata).

138 These features are also interspersed with kelp beds (Saccharina latissima) and patches of sea 
139 grass (Zostera marina). At low tide an expanse of seafloor extending up to $2.5 \mathrm{~km}$ from shore is

140 exposed at this site. The features of this site (patches of rocky intertidal interspersed among sand

141 and mud flats) are typical of the Minas Basin region (Daborn \& Pennachetti, 1979; Parker,

142 Westhead, \& Service, 2007), although the rocky areas here are somewhat more extensive than is

143 typical. The extent and accessibility of the seafloor off of Clarke Head thus presents

144 opportunities for considerable observation and study of a variety of marine life.

146 Green crab biological information:

147 Data collection during monitoring and subsequent analyses were informed (i.e. the data

148 partitioned and interpreted) based on information from the literature about green crab biology

149 (Crothers, 1967; 1968; Berrill, 1982; Klassen \& Locke, 2007). Among green crabs, the sexes can

150 be reliably distinguished at carapace width $(\mathrm{CW}) \geq 15 \mathrm{~mm}$ (Crothers 1967, 1968), which

151 corresponds to an age of 1-2 years. Female crabs become ovigerous at CW $\geq 30-40 \mathrm{~mm}$

152 depending on region (Klassen \& Locke, 2007). Maximum size for female crabs is $\sim 75 \mathrm{~mm} \mathrm{CW}$

153 whereas males can exceed $90 \mathrm{~mm} \mathrm{CW}$, and maximum crab lifespan is thought to be 3-7 years

154 depending on region (ca. 6 years in Maine; Berrill, 1982). In eastern North America, ovigerous

155 females are generally present in the summer, between June-October, and then larval release

156 occurs several weeks to months later in late summer or early fall (August-December, peak in

157 September). Once released, larvae develop through five planktonic larval stages (four zoeae and

158 one decapodid, commonly called a megalopa), lasting from ca. 24 to 82 days depending on water

159 temperature (Dawirs, 1985). The last larval stage then settles to the seabed between August and

160 October (Berrill, 1982; Klassen \& Locke, 2007). 
162 Sampling methodology:

163 Beginning in 2008, opportunistic sampling trips to Clarke Head were regularly undertaken up to

16416 times per year over the course of the summer (June-September) during the day at low tide

165 (Table 1). Preliminary surveys of the study area found almost no green crabs on sand, mud, or

166 mud-sand mix flats or in gravel areas during daytime low tides, so sampling was confined to

167 intertidal rockweed-covered reefs (black areas in Fig. 1C), which were the most suitable

168 intertidal habitats for crabs in the area and allowed for the most straightforward and repeatable

169 sampling protocol. Sampling was confined to the summer months because this is the time of the

170 year when crabs are most abundant on the intertidal and when most events of interest in their life

171 history take place (see above); also, crabs are largely absent from the intertidal in this region

172 during the winter.

173 During sampling trips, as many $1 \mathrm{~m}^{2}$ quadrats as tide and time allowed were haphazardly

174 sampled along all intertidal rockweed reefs located between approximately 7-10 $\mathrm{m}$ above chart

175 datum at the site (see Table 1 for annual and monthly sampling effort and Fig. 1B, C for the

176 distribution of reefs sampled). If they fell within a quadrat, any rocks were flipped and any

177 crevasses or rockweed were thoroughly searched. The number of green crabs present in the

178 quadrat was recorded, as was the size $(\mathrm{CW} \pm 1 \mathrm{~mm})$ and sex of all crabs found. Sex could be

179 determined for crabs with $\mathrm{CW}$ of $15 \mathrm{~mm}$ or greater based on the shape of the abdomen, which is

180 much broader in females than in males (Crothers, 1968). Any crabs found that were smaller than

$18115 \mathrm{~mm} \mathrm{CW}$ were classified as juveniles. Whether females were ovigerous (carrying eggs beneath

182 their abdomen) was also recorded. This allowed intertidal densities of crabs (number per $\mathrm{m}^{2}$ ) to

183 be calculated, as well as information on crab population dynamics such as mean sizes, sex ratios,

184 ovigerous female proportions, and juvenile abundances. 

areas, rather than hiding on the intertidal (Hunter \& Naylor, 1993). As such, intertidal surveys could underestimate crab abundances on their own. Many traditional and standard methods for sampling crab populations in both subtidal and intertidal areas exist, such as the use of Fukui traps in subtidal areas (McDonald et al., 2018) or intertidal pitfall traps that capture crabs that enter intertidal areas at low tide (Kent \& McGuiness, 2006). However, these methods require some specialized materials to build and expertise to use and maintain. The intertidal sampling program in the present study was established with no additional funding support and in such a way that non-scientist volunteers could readily assist in sampling. As such, sampling methods were initially confined to the daytime intertidal and kept as simple as possible (i.e. the use of quadrats), and in later years this approach was maintained for consistency. While this approach does have shortcomings (see Discussion), it allowed for a long time series that reasonably captured interannual changes in the crab population to be obtained. Nonetheless, to control for the potential issue of intertidal sampling missing larger, subtidal crabs, unintentional capture (i.e. bycatch) of large, subtidal green crabs (all $\geq 50 \mathrm{~mm} \mathrm{CW}$ ) during recreational flounder fishing trips was recorded. During a typical fishing trip (in years when the crab population was high), it was common for one to catch as many or more green crabs as flounder or other fish species (i.e. upwards of 5-10 or more crabs per hand-line; pers. obs. by author), so crab bycatch during such trips likely provides a good index of their abundance in subtidal areas. Data from up to 10 fishing trips per year were collected by consulting with local recreational fishers (Table 1). It was not possible to obtained detailed information of crab sex or size from these consultations, as fishers did not generally make such detailed observations. The total number of green crabs caught per year was divided by the total number of fishing trips per year from which information was 
208 obtained (number of fishers $\times$ number of trips) to create an index of annual catch per unit effort

209 (CPUE) of large subtidal crabs. While not equivalent to intertidal densities, this does give a

210 similar index of large, subtidal crab abundance and how it changed among years.

211

212 Statistical analyses:

213 Comparisons among years:

214 Intertidal densities (number of individuals $\mathrm{m}^{-2}$ ) of green crabs were calculated per each sampling

215 trip as the total number of crabs found in all quadrats during that trip divided by the total number

216 of $1 \mathrm{~m}^{2}$ quadrats sampled (see Table 1). During preliminary analyses, it was found that densities

217 did not differ significantly or in any consistent manner among sampling trips taken during

218 different months within each year (ANOVA, $\mathrm{F}_{3,35}=1.679, \mathrm{p}=0.189$ ), so all sampling trips

219 from the same year were pooled to make overall comparisons among years. Proportions of crabs

220 mature $(\mathrm{CW} \geq 15 \mathrm{~mm})$, proportion of mature crabs female, proportion of female crabs ovigerous,

221 total number of juveniles observed, and average size of crabs (overall and of different sexes)

222 were also calculated based on all crabs in each year.

223 Overall intertidal crab densities were compared among sampling years using a one-way

224 analysis of variance (ANOVA), in which the factor was year (treated as a categorical factor with

225 ten levels). If a significant effect of year was found, post-hoc comparisons were made among

226 years using Tukey's Honestly Significant Difference (HSD) test. Because the year 2013 showed

227 extremely reduced densities compared to all other years (see Results and Table 1), especially the

228 years preceding it (2009-2012), a further set of post-hoc comparisons of all other years against

2292013 was carried out using Dunnet's pairwise multiple comparison $t$-test. All of the

230 aforementioned analyses were carried out in IBM SPSS Statistics 23 (SPSS Inc., 2015). Overall 
231 mean values and $95 \%$ confidence intervals (C.I.s) were also calculated across the sampling

232 period (2008-2017) of intertidal density and subtidal CPUE to evaluate where specific years fell

233 in relation to these overall averages.

234

235

Comparisons among biological characters of the crab population:

236 As various biological characteristics of the green crab population at Clarke Head potentially

237 affecting its growth and recruitment dynamics (e.g., sex and size structure) were also quantified

238 in each year, whether the values of these characters in each year were correlated to changes in

239 crab abundance was tested (Table 2). Specifically, Pearson's correlation coefficient (r) values

240 and the associated p-value of the comparison of correlation coefficients against zero (Cohen,

241 West, \& Aiken 2003, Soper 2017) were calculated between average intertidal densities

242 calculated for each year $(\mathrm{N}=10$ pairs per comparison because there was only one value per year)

243 and the following biological characteristics of the crab population in each year: proportion of all

244 crabs that were mature $(\mathrm{CW} \geq 15 \mathrm{~mm})$, proportion of mature crabs that were female, proportion

245 of females that were ovigerous, mean size of all crabs, mean size of all females, mean size of

246 non-ovigerous females, mean ovigerous female size, mean male size, and total number of

247 juvenile crabs observed. Correlation coefficients were also calculated between each of these

248 biological predictor variables $(\mathrm{N}=10$ pairs $)$ to determine whether they could be included

249 together in later analyses. Whether annual subtidal CPUE of large crabs was significantly

250 correlated with mean annual intertidal density was also determined to assess to what extent

251 fluctuations in these values across years agreed.

252

253 Potential causes of changes in the sampled crab population: 
254 To investigate potential causes of fluctuations in the green crab population at Clarke Head, a

255 series of correlations, stepwise multiple regressions, and model selection analyses were carried

256 out. Only intertidal densities were evaluated in this way because they provided a larger sample

257 size (more sampling trips), and thus a more powerful analysis than could be achieved with

258 subtidal CPUE data. This approach was unlikely to have missed important patterns because

259 intertidal density and subtidal CPUE were strongly correlated (see Results).

260 As a first step, whether average annual intertidal densities were correlated with a number

261 of environmental (abiotic) measures potentially impacting crab recruitment or survival was

262 tested. Because conditions in different time periods might impact different phases of the crab life

263 cycle (e.g., effects on larvae in summer, adult or juvenile survival over winter), environmental

264 measures were averaged or otherwise calculated for each month of the year. Comparisons were

265 made between intertidal density in a year and environmental conditions in the summer and

266 autumn months (July-December) of the previous year and the winter, spring, and summer

267 months (January-September) of the same year; months in other seasons were not considered

268 because they were unlikely or unable to impact densities observed in the summer of a given year.

269 Air and water temperatures were considered because temperature in general has powerful

270 impacts on the physiology, survival, growth, moulting, and larval development of crustaceans,

271 including green crabs (Byrne, 2011; Dawirs, 1985, Nagaraj, 1993). Intertidal organisms like

272 green crabs are affected by water temperature specifically during high tides, and by air

273 temperature while exposed during low tides (Bertness et al., 1992; Scrosati \& Ellrich, 2018).

274 Precipitation, wind speed, and wind direction were considered because precipitation impacts

275 freshwater runoff and coastal salinity, which potentially impacts crab physiology (Nagaraj, 2003,

276 Klassen \& Locke, 2007), winds potentially impact larval retention during certain seasons 
277 (Bertness et al., 1996), and both wind and precipitation can indicate the frequency and severity of

278 storms impacting survival and movement of all life stages (Meehl et al., 2000). Variability in

279 abiotic features of the environment, such as temperature, can have distinct effects on organism

280 performance from those of mean values alone (e.g., Niehaus et al., 2012), so not only average

281 values of each environmental variable but also their variability were examined. The North

282 Atlantic Oscillation (NAO) index is an index of the difference in atmospheric pressure between

283 Iceland and the Azores, which is associated with large-scale climatic variability in the North

284 Atlantic Ocean (Hurrell et al., 2003). Large negative values of the NAO index have been

285 associated with cold and snowy conditions in eastern North America, including lower water

286 temperatures and salinity in the Gulf of Maine-Scotian Shelf system, which includes the Bay of

287 Fundy (Petrie, 2007). The NAO index may thus capture large-scale physical processes impacting

288 marine life, so it was also examined. Finally, variations in oceanographic circulation from year to

289 year can impact settlement by planktonic larvae of benthic invertebrates, and thus subsequent

290 recruitment to their populations (Bertness et al., 1992). Potential settlement predicted by

291 oceanographic dispersal models can indicate a role of oceanography in recruitment.

292 Most environmental data outlined above, including daily mean air temperature (in ${ }^{\circ} \mathrm{C}$ ),

293 variability (= standard deviation, or SD) of daily air temperature, minimum daily air temperature,

294 maximum daily air temperature, total daily precipitation (in mm), variability (SD) of daily

295 precipitation, maximum daily precipitation, direction of the maximum-speed daily wind gust(s)

296 (in tens of degrees relative to north $\left(0^{\circ}\right)$ ), variability (SD) of wind direction, mean daily wind

297 gust speed (in $\mathrm{km} \mathrm{h}^{-1}$ ), variability (SD) of wind gust speed, and maximum daily wind gust speed,

298 were calculated per month based on daily data from Environment Canada (Government of

299 Canada, 2018) as tracked at the weather station in Parrsboro, NS. Water temperature data in the 
300 form of monthly mean, SD, minimum, and maximum sea-surface temperature (SST) values

301 measured by satellite were obtained for the coordinates of Clarke Head from two different online

302 databases: for 2008-2012, data were obtained from the online SST database of Fisheries and

303 Oceans Canada (2018) (based on Casey et al., 2010), while for 2013-2017 they were obtained

304 from that of the International Research Institute for Climate and Society (2018) (based on

305 Reynolds et al., 2002). Air temperature provides a fair proxy for temperatures experience by

306 crabs, especially at low tide, because for half of each day intertidal crabs are exposed to air rather

307 than water temperatures (Boudreau \& Hamilton, 2012, Quinn, 2016); although the exact

308 temperatures experienced by crabs sheltering under macroalga-covered rocks at low tide are

309 likely less extreme than actual air temperatures (e.g., Scrosati \& Ellrich, 2018), these can still

310 provide an index of temporal fluctuations in temperatures experienced by crabs at low tide.

311 While not all crab life stages will be directly affected by SSTs (benthic juveniles and adults),

312 others will (larvae), plus SST data are more readily available and well-validated than bottom

313 temperatures are (Reynolds et al., 2002; Casey et al., 2010), and in a shallow, well-mixed area

314 with strong tides like the Minas Basin SSTs should provide a reliable index of temporal

315 fluctuations in temperature throughout the water column (Hetzel et al., 2015). Values of the

316 NAO index for each month were obtained from the Hurrell et al. (2003) database (National

317 Center for Atmospheric Research Staff, 2018). Oceanic circulation effects were assessed by

318 extracting potential total annual settlement (= total summer settlement) in the Minas Basin

319 predicted by a bio-physical oceanographic model of larval dispersal, originally developed for

320 American lobster (Quinn, Chassé, \& Rochette, 2017) but with development times of larvae

321 modified for eastern North American green crabs (after Dawirs, 1985). Both potential settlement 
322 in the previous and same year as density sampling were considered as potential predictors of crab 323 abundance.

324 Correlations of a grand total of 257 potential environmental predictor variables against

325 intertidal crab densities in the years 2008-2017 were thus tested by calculating Pearson's

326 correlation coefficient $(\mathrm{r})$ values. Whether each correlation coefficient was significantly $(\mathrm{p} \leq$

3270.05 ) different from a value of zero (with $\mathrm{N}=68$ pairs) was first assessed (Cohen, West, \&

328 Aiken, 2003; Soper, 2017). Any potential predictors that were not significantly correlated with

329 intertidal crab density were not considered further; 159 predictors were eliminated at this step

330 (see Supplementary Materials). Ten additional potential biological predictor variables

331 (population parameters such as sizes, sex ratios, etc.; Table 2) were also considered, but were

332 excluded from these analyses because they were all strongly and significantly correlated with

333 each other and most environmental predictors (see Supplementary Materials), meaning that they

334 would cause problems due to collinearity if included in multiple regression analyses (Grafen \&

335 Hails, 2002, Anderson, 2008); these variables were also significantly correlated with intertidal

336 density (see Results). The remaining 98 environmental predictors that were significantly

337 correlated with intertidal density were then further examined. The predictor variables that were

338 most strongly correlated with intertidal densities overall (i.e. those with the ten largest r-values),

339 as well as the most-strongly correlated variable of each type of data (air temperature, SST,

340 precipitation, wind speed, wind direction, NAO index, and potential settlement), were

341 determined and examined in more detail; five predictors occurred in both of these groups.

342 An additional comparison of interest was whether interannual changes in model-predicted

343 annual settlement agreed with observed abundances of juvenile crabs, as this might signal

344 whether processes affecting larvae in the plankton or affecting newly-settled juveniles had a 
345

greater impact on early benthic recruitment at this sites; therefore, the correlation between these values and its significance was also tested.

Next, a series of multivariate regressions were carried out to assess whether and to what extent multiple environmental factors may have impacted crab densities together. Because there were 98 potential predictor variables (most of which were significantly correlated with one another; see Supplementary Materials) but the maximum number of predictors that could be tested on this dataset ( $\mathrm{N}=68$ sampling trips) was nine, it was necessary to limit the analysis to simpler linear regression models and select a subset of potential predictors to be tested in them. Because many of the predictors among those with the top ten strongest correlations with intertidal density were similar types of variables (e.g., SST variables for the late winter-early spring months; see Results and Supplementary Materials), the set of seven predictors consisting of those of each type that were the most strongly correlated with density were used as the initial set of predictors in a series of stepwise multiple linear regression analyses (Grafen \& Hails, 2002). An initial regression model was thus tested that included all of these seven potential predictors as independent variables and intertidal density as the dependent variable (Table 3). Then, the independent variable with the highest, non-significant p-value was removed to generate a second model. This procedure was repeated until a model was produced that contained only significant independent variables. A null model (intercept-only) was also included so that other models could be compared against it. These statistical analyses were carried out in R v.3.1.1 (Team R Core 2014).

All models were evaluated using various metrics to assess how well they and the environmental variables included within them were able to capture interannual changes in green crab intertidal densities at Clarke Head. Values of $\mathrm{r}^{2}$ were generated to assess goodness of fit for 
368 each model, and Akaike's Information Criterion corrected for finite sample size (AIC ${ }_{C}$ ) was

369 calculated to determine the best model. $\mathrm{AIC}_{\mathrm{C}}$ is an index of the amount of useful information

370 contained within a model, and the best model out of all those tested is the one with the lowest

$371 \mathrm{AIC}_{\mathrm{C}}$ value (Anderson, 2008). $\mathrm{AIC}_{\mathrm{C}}$ is distinct from goodness of fit because though its value is

372 decreased based on model fit, it is increased based on model complexity (e.g., number of

373 parameters, $\mathrm{k}$ ), thus penalizing models for potential biases due to overfitting and collinearity

374 (Anderson, 2008). As correlations among predictor variables cause issues due to collinearity

375 (Grafen \& Hails, 2002, Anderson, 2008), whether the predictors included in the 'best' model

376 were significantly correlated was also checked before concluding it was indeed the best model.

Model $\Delta_{\mathrm{i}}$ and weights $\left(\mathrm{w}_{\mathrm{i}}\right)$ were also calculated. $\Delta_{\mathrm{i}}$ of a given model is simply that

378

379

380

381

382

383

384

385

386

387

388

389

390 model's $\mathrm{AIC}_{\mathrm{C}}$ value minus that of the best model (so best model $\Delta_{\mathrm{i}}=0$ ) and gives a measure of information lost by not using the best model; in general if a model's $\Delta_{\mathrm{i}}$ is greater than $12-16$ it is extremely unlikely to contain useful information, but a model with $\Delta_{\mathrm{i}}<2$ may still contain useful information, even if it is not the 'best' model (Anderson, 2008). Model $\mathrm{w}_{\mathrm{i}}$ is the 'likelihood' of a given model $\left(\right.$ model likelihood $=\operatorname{EXP}\left(-0.5^{*} \Delta_{\mathrm{i}}\right)$ ) divided by the sum of all models' likelihoods, and gives an indication of the 'distribution of evidence' among all models tested; if the best model has $\mathrm{w}_{\mathrm{i}}$ close to 1 there is little evidence that other models are useful, but if one or more non-best models has nonzero and relatively high weight then they may also be useful (Anderson, 2008). Finally, evidence ratios ( $\mathrm{w}_{\mathrm{i}}$ of one model divided by that of another) were calculated between specific models of interest, particularly the null model and the best model, to assess relatively how much evidence there was in favour of one model over another (Anderson, 2008). 
391

392

393

394

395

396

397

398

399

400

401

402

403

404

405

406

407

408

409

410

411

412

413

$\underline{\text { Additional information from Local Ecological Knowledge: }}$

Local recreational fishers asked to provide data to calculate subtidal crab CPUE were also asked

to comment upon any other occurrences of interest in the area over the course of the study

period, and particularly in 2013. All provided similar anecdotal observations regarding changes

in abundances and presence/absence of particular species in the area that are potential predators or prey of green crabs. These observations are briefly reported in the Results and discussed.

\section{Results:}

Interannual changes in overall crab densities:

The density of green crabs at Clarke Head, NS observed on the intertidal zone differed significantly overall among years from 2008-2017 (ANOVA, F 9, 58 $=4.461, \mathrm{p}<0.001$; Fig. 2). Intertidal densities increased from 2008 to 2010, when peak abundances were observed, remained relatively high in 2011 and 2012, and then rapidly declined to all-time lows in 2013 (Fig. 2). Densities remained low after 2013, but did gradually increase from 2014 to 2017 (Fig. 2). Densities were also highly variable among samples in 2008-2012, but from 2013 onward they were consistently low (compare error bars in Fig. 2). Intertidal densities were highest and aboveaverage in the years 2010-2012, and lowest and below-average from the years 2013-2016 (Fig. 2). Intertidal densities in 2010 were significantly higher than those in 2013, 2014, and 2015 (Tukey's HSD test, $\mathrm{p} \leq 0.034$ ) (Fig. 2). The difference between densities in 2010 and 2012 was marginally non-significant (Tukey's HSD test, $\mathrm{p}=0.053$ ), and differences among densities in all other years were not statistically significant (Tukey's HSD test, $p \geq 0.096$ ) (Fig. 2). Average intertidal densities in 2013 in particular were much lower (by 13.3-91.4\%) than those in other years; 2013 densities were significantly lower than those in 2010 and 2012 (Dunnet's test, both p 
$414=0.001)$, but did not significantly differ from those in any other year before $(2008,2009,2011$ :

415 Dunnet's test, $\mathrm{p} \geq 0.172$ ) or after this (2014-2017: Dunnet's test, $\mathrm{p} \geq 0.809$ ) year (Fig. 2).

416

417 Changes in population size structure, sex ratios, and recruitment among years:

418 Green crabs of nearly all possible sizes, from juveniles $\leq 5 \mathrm{~mm} \mathrm{CW}$ up to adult males of $86 \mathrm{~mm}$

419 CW, were found at Clarke Head, NS over the ten years of sampling, although crabs larger than

$42050 \mathrm{~mm} \mathrm{CW}$ were always uncommon on the intertidal (Fig. 3A-J). In most years preceding 2013,

$42183.4-91.0 \%$ of the crabs observed were mature (i.e. $\geq 1-2$ years old and with $\mathrm{CW} \geq 15 \mathrm{~mm}$ ) (Fig.

422 4A), a wide range of crab sizes were observed (Fig. 3A-E), and overall average sizes of crabs

423 were relatively typical or large for an intertidal population (28.2-52.8 $\mathrm{mm} \mathrm{CW}$; Boudreau \&

424 Hamilton, 2012) (Fig. 4B). Notably higher proportions of sampled crabs in larger size classes

425 were observed in 2010-2012 than in other years (Fig. 3A-E), the same years in which crab

426 abundances were also highest (Fig. 2). In 2013, a dramatic shift occurred in which the proportion

427 of mature crabs in the area plummeted to $58.1 \%$ (Fig. 4A), mean sizes of all crabs found

428 decreased to $15.7 \mathrm{~mm} \mathrm{CW}$ (Fig. 4B), and crabs of CW > $30 \mathrm{~mm}$ almost completely disappeared

429 from the intertidal (Fig. 3F). In subsequent years (2014-2017) larger crabs (up to $77 \mathrm{~mm} \mathrm{CW}$ )

430 began to reappear, but still remained much less abundant than in previous years (Fig. 3G-J), and

431 the proportion of mature crabs (56.3-68.8\%) and mean overall crab sizes (17.1-26.6 mm CW)

432 remained lower than they were before 2013 (Fig. 4A, B). Further, even with this gradual return

433 of larger crabs total crab abundances (densities) remained low in 2014-2016 (Fig. 2); although in

4342017 intertidal density did climb to a value near the overall average (Fig. 2). Mean sizes and size

435 distributions of male, female, and ovigerous female crabs similarly shifted toward smaller sizes 
436 in 2013-2016 than in 2008-2012, with some sign of returns to pre-2013 values occurring in 2017 437 (Fig. 3F-J, 4A, B).

438 The intertidal population sampled was in general female-dominated (average proportion 439 of mature crabs female $\pm \mathrm{SD}=0.580 \pm 0.082$, maximum $=0.700$ in 2010), except in one year 440 (2014, proportion females $=0.438)($ Fig. 4A). Sex ratios in this population fluctuated 441 considerably among years, but with no clear overall pattern except perhaps a slight decrease in 442 the proportion of females among sampled crabs from $0.670-0.700$ in the earliest years sampled 443 (2008-2010) to $0.438-0.614$ in later years (Fig. 4A). About $50 \%$ of females observed were 444 ovigerous in all years (average proportion $=0.540 \pm 0.083$, range $=0.357-0.629$ ), and this 44 proportion fluctuated among years without any clear pattern except that ovigerous females were 446 notably rarer in 2012 than in other years (Fig. 4A). Ovigerous females tended to be larger than 447 non-ovigerous ones in this population, and also were often larger on-average than males (Fig. 448 3A-J, 4B), though it should be noted that very large males were also often present (Fig. 3A-J). The abundance of juvenile $(\mathrm{CW}<15 \mathrm{~mm})$ crabs observed on the intertidal at Clarke 450 Head also varied considerably among years, but with no clear pattern (Fig. 5A). Juvenile 451 numbers were notably very low in 2011 and 2013, and very high in 2012 (Fig. 5A). Subtidal 452 CPUE of large crabs was relatively high and above-average from 2008-2012 and relatively low 453 and below-average from 2013-2017 (Fig. 5B). Subtidal CPUE thus underwent similar 454 fluctuations to intertidal densities (Fig. 2), although the year 2008 was an exception in which 455 intertidal densities were relatively low (Fig. 2), while subtidal CPUE was average (Fig. 5B). 456

457 Correlations among biological characteristics and intertidal densities: 
458 All biological characters of the sampled crab population discussed above (sizes, sex ratios, etc.)

459 were strongly and significantly correlated with observed intertidal crab densities (Table 2).

460 Specifically, mean sizes of all, male, all female, ovigerous female, and non-ovigerous female

461 crabs, the proportion of the crab population mature, the proportion of mature crabs that were

462 female, and juvenile abundances were positively correlated with intertidal density (Table 2).

463 Interestingly, however, the proportion of female crabs that were ovigerous was strongly

464 negatively correlated with intertidal density (Table 2), which was likely driven in large part by

465 the relatively low abundance of ovigerous females in 2012 (Fig. 4A). Intertidal densities and

466 subtidal CPUE showed similar fluctuations over time, and thus were positively correlated with

467 each other between 2008 and $2017(\mathrm{r}=+0.521, \mathrm{~N}=68, \mathrm{p}<0.001)$. Observed juvenile abundance

468 and model-predicted annual settlement were likewise positively correlated $(r=+0.375, N=10, p$

$469=0.286$ ), although since the correlation between these two metrics was relatively weak and non-

470 significant this likely indicates some decoupling between pre- and post-settlement processes

471 affecting new crab recruit numbers in nature (see Fig. 5A).

472

473 Potential correlates and causes of interannual changes to green crab abundances:

474 Of the 257 environmental variables considered as potential predictors of changes in green crab

475 abundances across years, 98 were significantly correlated (i.e. $\mathrm{r}<-0.238$ or $\mathrm{r}>+0.238, \mathrm{~N}=68, \mathrm{p}$

$476 \leq 0.05$ ) with intertidal crab densities (Supplementary Materials). All of the predictors among

477 those with the top ten strongest correlations had positive and significant r-values $\geq 0.5$ (Fig. 6A-

478 I). The strongest correlation was a positive one between the maximum SST during March of the

479 same year and intertidal density $(r=+0.560, N=68, p<0.001$; Fig. 6A). Five of the remaining

480 predictors out of those with the ten strongest correlations with intertidal density included SST 
481 parameters for the early months (February-April) of the same year as that in which densities

482 were measured (Fig. 6B, C, E-G; Supplementary Materials), specifically the maximum February

483 SST, minimum March SST, and the mean, SD, and maximum of April SST. All of these SST

484 predictors were positively correlated with density, meaning that higher SSTs during late winter-

485 early spring led to higher densities, while lower SSTs led to lower densities (Fig. 6B, C, E-G).

486 The top ten predictors most-strongly correlated with density also included the mean wind speed

487 in the previous year's October (Fig. 6D), total annual settlement in the same year $(\mathrm{r}=+0.520, \mathrm{~N}$

$488=68 . \mathrm{p}<0.001$; compare Fig. 2 vs. Fig. 5A), maximum air temperature in March of the same

489 year (Fig. 6H), and the variability (SD) of total precipitation during July of the previous year

490 (Fig. 6I), all of which were positively correlated with density. The wind direction variable most

491 strongly correlated with density was the average wind direction in October of the previous year,

492 which had the $12^{\text {th }}$ highest $r$-value overall and was positively and significantly correlated with

493 density (Fig. 6K). The most-strongly correlated NAO index variable was that for July of the

494 previous year, which had the $36^{\text {th }}$ highest r-value overall (see Supplementary Materials) and was

495 significantly and negatively correlated with density (Fig. 6L).

496 Additional interesting predictor variables showed correlations with lower, but still

497 significant values (i.e. $\mathrm{r}$ between $+/-0.238-0.5$ ). For example, most SST and air temperature

498 variables for the winter, spring, and summer months of the same year were positively correlated

499 with intertidal density (see Supplementary Materials), meaning that colder winters, springs, and

500 summers resulted in lower crab numbers ; however, several mean and minimum SSTs and air

501 temperatures during the summer and early fall of the previous year (July-October) were

502 significantly negatively correlated with density (see Supplementary Materials), meaning that

503 warmer summers resulted in lower intertidal densities in the following year. SSTs were generally 
504 better predictors of intertidal density than air temperatures were, while precipitation and 505 especially wind variables were overall less well-correlated with densities than these (Fig. 6A-C,

506 E-H, J; Supplementary Materials). Crab density in a given year was also significantly correlated 507 to the value of the North Atlantic Oscillation (NAO) index in certain months within the summer 508 or early autumn of the same or previous year, but not in other seasons (Fig. 6L; see

509 Supplementary Materials). Specifically, higher or more positive values of the NAO index in the 510 preceding year's July and August and the same year's June and August were associated with 511 lower crab densities in a given year, while higher NAO index values in the preceding year's 512 September were associated with higher crab densities (see Supplementary Materials); all other 513 periods' NAO index values were not significantly correlated with intertidal densities.

514 Stepwise multiple regression resulted in six models to describe changes in intertidal crab 515 densities across years based on up to seven potential predictors, which represented the best 516 individual predictors (i.e. highest r-values) of each type of variable examined (Table 3;

517 Supplementary Materials). The best model (\#6) explained $40.7 \%$ of the interannual variation in 518 intertidal density by related it to two environmental predictor variables: total annual potential 519 settlement and maximum March SST, both in the same year (Table 3). Both predictors included 520 in the best model were not significantly correlated with one another, although some of those 521 included in other non-best models were (see Supplementary Materials). The variables in the best 522 model therefore provided perhaps the best explanation of observed changes to intertidal crab 523 densities. However, all models were much better than a null (\#0, intercept-only) model (evidence 524 ratio of all models versus the null $=10823.771-693128.818)$ and had comparable $\mathrm{r}^{2}$-values 525 (0.369-0.407) to each other (Table 3). Also, although the best model (\#5) carried most of the 526 model weight $\left(\Delta_{\mathrm{i}}=0, \mathrm{w}_{\mathrm{i}}=0.355\right)$, the second- and third-best models may also have contained 
527 additional useful information (Table 3). Specifically, the second-best model (\#5), containing the

528 same predictors as the best model in addition to the mean wind direction in October of the

529 previous year, had an $\mathrm{AIC}_{\mathrm{C}}$ value almost the same as that of the best model $\left(\Delta_{\mathrm{i}}=0.114\right)$ and a

530 model weight of 0.335 (Table 3). The third-best model (\#4), containing the same predictors as

531 model \#4 plus the NAO index value in July of the previous year, also had a $\Delta_{\mathrm{i}}$-value $<2\left(\Delta_{\mathrm{i}}=\right.$

$5320.997)$ and carried some weight $\left(\mathrm{w}_{\mathrm{i}}=0.215\right.$; Table 3$)$. Therefore these other variables may also

533 have had some influence on interannual fluctuations in this crab population.

534

535 Local Ecological Knowledge of changes in the study area:

536 In addition to green crab bycatch during fishing being high prior to 2013 and then very low

537 afterwards, recreational fishers reported changes to other bycatch finfish species that may have

538 implications to green crabs. Longhorn sculpin (Myoxocephalus octodecemspinosus) were always

539 a frequent bycatch species in this area, but from 2013 onward they became an extremely

540 abundant nuisance species to fishers. Cunners (Tautogolabrus adspersus) were first caught by

541 fishers off of Clarke Head in 2012 and have been present in the area since, but before this no

542 fisher interviewed had ever encountered one. Many of the fishers consulted also frequently

543 harvested marine worms from sand- and mudflats in the area, a practice often done at nighttime

544 low tides. A frequent observation by local marine worm harvesters in the area prior to 2013 was

545 that during nighttime low tides green crabs were extremely abundant on sand- and mudflats,

546 where they frequently preyed on marine worms (e.g., Alitta virens). However, from 2013

547 onwards encounters with crabs on such excursions become very rare. Further, the marine worms

548 used as bait by fishers ('shad-worms', a local name around Parrsboro, NS for mainly sandworms

549 such as the king ragworm, Alitta virens; Wilson \& Ruff, 1988; Miller, 2009) were also observed 
550 by local recreational fishers to become extremely rare in 2013 in sand- and mudflat areas near

551 Clarke Head in which they were previously abundant, and have remained so since then. Locals

552 were of the opinion that excessive predation by green crabs led to the collapse of worm stocks in

553 2013, which in turn led to crab starvation and die-off.

554

555 Discussion:

556 The present study presents a ten-year dataset obtained by monitoring a single, established

557 population of invasive green crabs (Carcinus maenas) in the Minas Basin of the upper Bay of

558 Fundy, Atlantic Canada. Monitoring of densities, size structure, sex ratios, and reproductive

559 ratios of intertidal crabs revealed a marked wholesale decline in this population occurring within

560 the year 2013. This decline in 2013 was associated with a shift in the population's demographic

561 structure towards smaller-sized and fewer sexually-mature or reproductive (i.e. ovigerous) crabs,

562 and these changes have largely persisted through subsequent years. These changes to the crab

563 population were significantly correlated with various environmental variables, suggesting some

564 change to the physical conditions experienced by crabs in the area during or after 2013. Although

565 correlations do not equal causation, the links established herein between interannual changes in

566 crab biology and their physical environment are highly suggestive, and provide directions that

567 can be pursued by future research.

568 There are several important aspects of the monitoring program that could be improved in

569 the future and may have led to some uncertainty regarding specific numbers (e.g., crab densities,

570 water temperatures) in the present study. Most importantly, the use of daytime intertidal quadrats

571 to simplify the monitoring of the population has the potential to have missed important trends

572 and to be inconsistent with results of other studies of crabs in the study region that used more 
573 standard methodologies (e.g., Fukui or pitfall traps; MacDonald et al., 2018). Crabs would

574 almost certainly have been more abundant and present over other areas of the intertidal (not just

575 in shelters among reefs) if sampling had been done at night, when crabs are more active and

576 likely to stay on the intertidal due to lower air temperatures, water stress, and visibility to

577 terrestrial predators compared to daytime (Crothers, 1968; Klassen \& Locke, 2007). LEK

578 observations reported by local fishers of reduced crab activities during nighttime worm

579 harvesting activities in and after 2013 do suggest that, even if sampling had been done at night,

580 the reduction in crab numbers in 2013 would have been observed; although this is unconfirmed

581 at present. The use of simplified intertidal quadrats instead of standard Fukui traps in this study

582 means that the densities quantified herein are not directly comparable to those collected in other

583 studies in the region (e.g., MacDonald et al., 2018), which does impair the possibility of direct

584 comparisons across studies. Crabs also undergo tidal migrations (Hunter \& Naylor, 1993), and

585 because sampling focused mainly on intertidal crabs no information was obtained regarding what

586 proportion of the crab population left the intertidal zone for the subtidal on ebb tides, and

587 whether this changed among years. Declines in the CPUE of large (>50 $\mathrm{mm} \mathrm{CW})$ subtidal crabs

588 caught during flounder fishing trips in and after 2013 were noted, which lent support to the

589 conclusion that this decline was a real event that impacted the entire local crab population, and

590 not just the result of crabs migrating away from the intertidal for some reason more in later years

591 (Hunter \& Naylor, 1993). However, because the catchability of green crabs by flounder fishing

592 hooks was not formally quantified (though it did seem to be high, see Methods) and the

593 proportion of crabs leaving the intertidal at low tides was unknown, these results are not without

594 some degree of uncertainty. Future monitoring work within this population should attempt to

595 quantify these variables, as well as attempt to sample crab densities at night and using Fukui 
596 traps, to confirm the conclusions drawn herein and improve the quality of future data obtained. A

597 more thorough and formal analysis of spatial and temporal variations in crab numbers at this site

598 (among tidal elevations (Scrosati, Grant, \& Brewster, 2015), sampling dates within a year, etc.)

599 would likely also be worthwhile. Direct monitoring of environmental variables at the site, such

600 as temperatures (air at low tide only, and water at high tide), could also improve future analyses

601 of the drivers of population changes. However, while specific numbers may not have been

602 assessed with perfect accuracy, the magnitude of the change observed at and after 2013 as

603 captured over this ten-year monitoring program is unequivocally a real and important result.

604 The lack of substantial recovery of this population to its former characteristics from 2014

605 to 2017 could be a result either of slow growth due to reduced reproductive capacity (i.e. loss of

606 larger, mature individuals), and/or due to the cause of the initial decline still being in play within

607 the environment inhabited by these crabs. Better understanding of the potential causes of this

608 decline is needed to fully examine the scope and implications of this change. However, the

609 negative implications of the observed loss of breeding stock to this population's future growth

610 and stability is obvious, particularly with the loss of larger individuals that are thought to have

611 considerably greater size-specific-fecundity in decapod crustaceans than smaller breeders

612 (Somers, 1991; McGaw, Edgell, \& Kaiser, 2011). The ability of crabs to feed on shelled prey is

613 also strongly size-dependent, such that smaller crabs have access to a more limited suite of prey

614 than larger one (Elner \& Hughes, 1978), so the shift in population size structure may also have

615 implications to crab foraging ecology and to prey species and their communities in the region.

616 Even in 2017, when observed overall crab densities appear to have begun approaching 'normal'

617 levels for this study site and period and some large crabs were present on the intertidal, juvenile

618 crabs still made up a substantial portion of the population and average sizes were smaller than in 
619 pre-2013 conditions. Whether this population will fully recover and how long it will require to 620 do so are open questions, but because crabs interact strongly with many species (e.g., Klassen \& 621 Locke, 2007; Boudreau and Hamilton, 2012) if recovery is slow or does not occur the ecology of 622 the study area could change considerably; thus monitoring should and will continue. It is important to note that intertidal crab densities at Clarke Head were comparably low in 2008 to those seen in and after 2013, and these low densities were associated with some 625 similar environmental factors to those putatively involved in the 2013 decline (e.g., oceanographic currents leading to low predicted settlement). However, lower abundances in

6272008 were not associated with differences in the size or reproductive structure of this population 628 or low subtidal CPUE versus other years, whereas in 2013 larger, sexually mature crabs become 629 extremely scarce and subtidal CPUE was very low. One could postulate some similar factors 630 having been in play in 2007-2008 to those in 2012-2013, but with additional factors from 20126312013 and thereafter (discussed below) leading to particularly high losses of larger, breeding 632 crabs. As a result, the population recovered quickly in 2009 from 2008 declines, but as of 2017 633 had not fully-recovered from the 2013 collapse.

634 Results of this study showing population declines of a benthic marine invertebrate in 635 2013 agree with findings of other studies and species in the Bay of Fundy-Gulf of Maine region.

636 Kienzle (2015) and MacDonald et al. (2018) noted a decline in abundances of green crabs 637 inhabiting sites in Chignecto Bay, a nearby but distinct branch of the upper Bay of Fundy to the 638 Minas Basin (Fig. 1), from 2013 to 2014. Monitoring of early benthic recruitment (i.e. 639 settlement) of American lobster (Homarus americanus) juveniles by the American Lobster 640 Settlement Index (ALSI) recorded record-low recruitment of juveniles in the year 2013 641 throughout most of the Bay of Fundy, Gulf of Maine, and southwestern Nova Scotia (Wahle \& 
642 Carloni, 2017). Lobster recruitment since 2013 in these areas has remained low compared to its

643 pre-2013 values and appears to have been even lower than in 2013 in the year 2016 (Wahle \&

644 Carloni, 2017). Potential settlement of lobster larvae in the Gulf of Maine-Bay of Fundy system

645 and the Scotian Shelf has also been predicted by a bio-physical dispersal model of the species'

646 range (Quinn, Chassé, \& Rochette, 2017) to have been extremely low in 2013 (B.K. Quinn, J.

647 Chassé, and R. Rochette, pers. comm.). Benthic recruitment of soft-shell clam (Mya arenaria)

648 settlers monitored on mudflats in the Bay of Fundy was also extremely low in 2013 compared to

649 earlier years (Clements, 2016). Along with the present study, these various observations point to

650 the occurrence of some sort of large-scale oceanographic event in the region of the Bay of Fundy

651 during or around the year 2013. This event appears to have negatively impacted numerous

652 marine species in the region, and as of 2017 many species' populations have still not completely

653 recovered. If such an event occurred, what were the causes or mechanisms? Results of the

654 present study and postulated causes of declines reported in others may provide some hints, as

655 discussed below.

656 Recent climate change has had important impacts on thermal variability within the

657 atmosphere and the ocean, including warmer summers and periodically colder, harsher winters in

658 temperate regions such as Atlantic Canada (Petrie, 2007; Mills et al., 2013; Kienzle, 2015;

659 MacDonald et al., 2018). When extremes of seasonal temperatures coincide due to such climatic

660 changes, the effects on biota can be considerable (e.g., Quinn, 2016). Excessively hot summers

661 in recent years may have played a role in observed declines because heat stress leads to

662 decreased performance and survival in decapod crustaceans, especially in larger-bodied benthic

663 life stages that tend to have lower heat tolerances (e.g., Byrne, 2011). The Gulf of Maine is now

664 widely-acknowledged to have experienced an 'ocean heat wave' in 2012, which led to negative 
665 heat stress effects on many species, and changes to phenology (e.g., moulting by lobsters) of

666 many others (Mills et al., 2013). This heat wave likely contributed to results of the present study,

667 as higher temperatures during the summer months of a given year were correlated with lower

668 crab densities in the following year, with 2012, the year preceding 2013, having one of the

669 hottest summers recorded (see Supplementary Materials). Of course, crab densities in the

670 monitored population were actually quite high during the summer of 2012, implying that rather

671 than being stressed crabs were experiencing temperatures close to optimal for their survival and

672 growth. Although it is important to note that ovigerous females were less frequently encountered

673 on the intertidal in 2012 compared to other years, which may mean that this very warm summer

674 had negative impacts on the survival or reproduction of females. Negative effects of the 2012

675 heat wave on crab abundances in 2013 may alternatively have occurred via some indirect means,

676 such as effects on prey or predator species, altered phenology, or perhaps accumulated sub-lethal

677 stress effects from the previous year if supra-optimal temperatures had occurred.

678 Cold winters and springs may also have contributed to crab declines in 2013 onward,

679 since crab survival at all life stages - but especially overwintering survival of young-of-the-year

$680-$ is adversely affected by low $\left(<6-10^{\circ} \mathrm{C}\right)$ temperatures (Berrill, 1982; Klassen \& Locke, 2007).

681 Therefore, Kienzle (2015) and MacDonald et al. (2018) postulated that especially harsh, cold

682 conditions during the winter from 2013-2014 likely contributed to the declines they observed in

683 green crab numbers in Chignecto Bay. In the present study, crab intertidal densities in a given

684 year were also found to be positively correlated with mean temperatures during the preceding

685 winter and early spring months (i.e. colder winter and spring = fewer crabs); while the data

686 examined herein do not suggest that the winter of 2013 was particularly cold (at least for the

687 studied part of the Minas Basin), it was colder than that of preceding years, and the winters of 
6882014 and 2015 were notably cold (see Fig. 6A-C, E-H, J). However, it is possible that the 689 combined negative effects of the very warm summer of 2012 on larger adult life stages and the 690 somewhat cold winter of 2013 on earlier life stages could have led to some of the declines 691 observed; this disparity in thermal extremes may also explain why numbers of larger crabs, 692 which would have overwintered and experienced both extreme temperature conditions, were 693 observed to have declined relatively more than smaller crabs in 2013. abundances included greater wind speeds from a more southeasterly (i.e. towards a more northwestern direction, of higher degree values relative to north) in the preceding autumn (October) and greater variability in precipitation during the early summer (July) of the previous year (for more details, see Results, especially Table 3 and Fig. 6D, I, K). The exact roles of these factors and other wind- and precipitation-related predictors (see Supplementary Materials) are complex, as different impacts in different seasons may affect one or more different life stages.

Winds and precipitation, for example, may signal storm frequency, with more frequent storms being expected to have negative impacts on both planktonic larvae and benthic adults and juveniles (e.g., Jury, Howell, \& Watson, 1995; Moksnes et al., 2014). Wind speed and direction impact surface currents and water circulation, so during the summer and autumn these can impact whether and how many larvae are retained versus dispersed (Bertness, Gaines, \& Wahle, 1996), thus affecting settlement and recruitment to benthic populations (Crothers, 1967; Moksnes et al., 2014). Reduced salinity resulting from high precipitation can adversely affect physiological health and survival of larvae in the surface waters directly and benthic life stages indirectly via runoff (Nagaraj, 1993; McGaw, Reiber, \& Guadagnoli, 1999; Klassen \& Locke, 2007). The positive correlations found in this study of crab abundance with summer precipitation 
711 and autumn winds are somewhat unexpected. It is conceivable that these atmospheric forces alter

712 circulation at or beneath the sea surface in such a way that is actually beneficial to crabs - for

713 example, by directing settling larvae shoreward or forcing saline water to flow into the estuary in

714 response to wind-induced surface currents. Indeed, given the orientation of Clarke Head (Fig.

715 1C) more southeasterly winds in the autumn, blowing towards the northwest, would potentially

716 help to direct larvae in surface currents toward the shore at this site and facilitate greater

717 settlement there, while winds in the opposite direction could impede larval transport toward the

718 coast. The strong positive correlation between model-predicted settlement - essentially a proxy

719 for oceanography - and crab abundances lends some support to this supposition. However, this

720 requires further study of the interaction of weather and oceanography in the study area to be

721 confirmed and clarified.

722 It is interesting that in years in which oceanographic conditions leading to higher

723 potential settlement occurred the abundance of crabs older than one year $(>15-20 \mathrm{~mm} \mathrm{CW}$;

724 Crothers, 1967; 1968; Klassen \& Locke, 2007) was also higher, and conversely when there was

725 less settlement older crab abundances were also low. Clearly decreased settlement cannot explain

726 low mature crab abundances in years such as 2013. However, these results do offer the intriguing

727 suggestion that oceanographic conditions favouring settlement of larvae in the studied region

728 also favour survival of older crabs. Given that the study site is located in a relatively shallow,

729 well-mixed estuary, it is conceivable that this might be the case.

730 If indeed some large-scale oceanographic event was responsible for crab declines in

7312013 and declines of other species in the region, one of the environmental variables examined

732 which would be expected to have had an impact was the value of the NAO index. The winter

733 NAO in particular has been found to be strongly associated with climate and ocean 
734 characteristics (Hurrell et al. 2003), such that in years with highly negative values of the winter

735 NAO index bottom waters in the Bay of Fundy-Gulf of Maine system (including the southwest

736 NS Shelf) have relatively low salinity and are colder than average, whereas in years with strong

737 positive winter NAO index values waters in this region become warmer and more saline (Petrie,

738 2007). Negative winter NAO index-years also tend to have more frequent storms and stronger

739 offshore-directed currents in this region than positive years (Hurrell et al., 2003, Petrie, 2007).

740 The year 2013 had somewhat negative NAO index values during the winter months (see

741 Supplementary Materials), which may mean that conditions in the Bay of Fundy were

742 unfavourable for survival of benthic marine species and retention and recruitment of their

743 planktonic larvae; observations cited for various species in this region certainly suggest that

744 NAO is negatively correlated to abundance and population recruitment (Kienzle, 2015,

745 Clements, 2016, Wahle \& Carloni, 2017). However, even greater negative values of the NAO

746 index occurred in the winter of 2010, when summer crab densities observed herein were at their

747 highest. Indeed, while significant correlations between crab densities and NAO index values for

748 the summer months were found in this study, most were negative, such that more negative NAO

749 indices were associated with higher crab abundances. However, NAO index values in winter

750 months and other seasons were not significantly correlated with crab densities. This is

751 unexpected, but does agree with other correlations (e.g., the positive relationship between

752 precipitation and wind speeds during spring and summer months and crab densities; see

753 Supplementary Materials). Clearly the relationship between the NAO index and localized

754 recruitment is thus not as simple or direct in all cases as might be supposed. Perhaps the Minas

755 Basin, being relatively isolated from the rest of the Bay of Fundy-Gulf of Maine system, is less

756 affected by NAO-associated shifts in regional oceanography or climatology. Future studies 
757 should further examine the relationship between the NAO index and recruitment in other marine

758 species in the region to clarify these complexities.

759 Crab populations could alternatively have declined due to biotic changes in the studied

760 region, such as those cited by local recreational fishers concerned with other species potentially

761 interacting with crabs. Increased presence in the area of two finfishes known to feed on benthic

762 crustaceans such as smaller crabs (Klein-MacPhee, 2002; Munroe, 2002) in 2012-2013 may have

763 played a part in crab declines. Cunner (Tautogolabrus adspersus) were largely absent from the

764 inner Bay of Fundy prior to 2012 (Munroe, 2002), but then in 2012 they began to penetrate

765 deeper into the bay (Woodard, 2018). Cunner numbers in the Bay of Fundy have since been

766 lower than those in 2012, but nonzero (Woodard, 2018). Longhorn sculpin (Myoxocephalus

767 octodecemspinosus) are native to the Minas Basin (Klein-MacPhee, 2002; Parker, Westhead, \&

768 Service, 2007), but from 2013 onward they have become extremely abundant in the Minas Basin.

769 The extent to which these fish species prey on green crabs and their impact on crab populations

770 needs to be better quantified to determine whether predation by them could be responsible for

771 crab declines. Declines to populations of species preyed on by green crabs in the area, such as

772 the decline in sandworm (Alitta virens) stocks reported by recreational harvesters, may also be

773 related to crab declines. Green crabs will prey on sandworms (Crothers, 1968; Klassen \& Locke,

774 2007), so it is quite possible that predation by the invasive crab population on these worms in

775 combination with worm harvest (potentially overharvest) by humans (Miller, 2009) could have

776 contributed to the worm population's collapse (though this needs further study). However, green

777 crabs are quite capable of feeding on a wide variety of prey species also present off of Clarke

778 Head, including blue mussels (Mytilus spp.), barnacles (Semibalanus balanoides), periwinkles

779 (Littorina spp.), dogwhelks (Nucella lapillus), soft-shell clams (M. arenaria), and many others 
780 (Klassen \& Locke, 2007). All of these species were present and quite abundant throughout the

781 2008-2017 period (pers. obs. by author), so even if crabs had relied heavily on sandworms as a

782 food source they should have been readily able to switch their prey to any of the various other

783 species present (Huntingford \& Taylor, 1997) when the worm stock declined in 2013. While

784 unconfirmed, these observations by locals provide interesting directions for future research to

785 pursue.

786 Some additional or alternative localized factors that may also have been impacting crab

787 populations within the Minas Basin during or since 2013 could include: development of tidal

788 power within the Minas Channel, the only means of connectivity between the Minas Basin and

789 the remainder of the Bay of Fundy (Parker, Westhead, \& Service, 2007; Copping et al., 2016);

790 increasing eutrophication in recent years within the adjacent estuary, causing harmful algal

791 blooms ('red tides') that cause anoxia and produce toxins potentially harmful to crustacean

792 development (e.g., copepod: Miralto et al., 1999); effects of ocean acidification on crab

793 exoskeleton formation and moulting (Clements, 2016; Miller et al., 2016); changes in the

794 phenology (timing) of planktonic productivity on which larval diet and survival depends

795 (Scrosati \& Ellrich, 2016; Wahle \& Carloni, 2017); or others. However, the impact of all of these

796 listed factors requires further directed study before a link to crab declines can be drawn.

797

798 Conclusions:

799 To conclude, there is much evidence that is suggestive that some sort of physical oceanographic

800 and/or climatic event occurred in or around 2013 and impacted marine biota in the Bay of Fundy

801 and Gulf of Maine, and this should certainly be investigated further. Results of the present study

802 strongly suggest that the observed decline of the green crab population at Clarke Head was at 
803 least partially due to this event. There are important demographic and ecological implications to

804 other benthic species in the Bay of Fundy-Gulf of Maine region if they have been or are still

805 being impacted similarly to this green crab population by an oceanographic event in or beginning

806 in 2013. If invasive species are indeed more vulnerable to climatic changes than native ones

807 (e.g., Kienzle, 2015; MacDonald et al., 2018), then these observations of green crab declines

808 should serve as a warning of potential changes to other species in the study region, such as native

809 rock crabs or American lobsters. Continued monitoring of this population and further study of

810 other species will be needed to confirm the causes of these observed shifts, their impacts, and

811 whether populations will continue to be negatively impacted.

812

813 Acknowledgements:

814 The author thanks the many individuals that assisted in field sampling and contributed

815 information from local recreational fishing at Clarke Head, NS, especially J. Hardy Best and

816 Kelly Quinn of Parrsboro, NS. Jeff Clements, Krystal Woodard, Heather Hunt, and Rémy

817 Rochette of the University of New Brunswick and Joël Chassé of Fisheries and Oceans Canada

818 are also thanked for information about cunners, clams, and lobster settlement and dispersal.

\section{References:}

821 Anderson DR. 2008. Model Based Inference in the Life Sciences: A Primer on Evidence. New

$822 \quad$ York, NY: Springer Science+Business Media, LLC.

823 Berrill M. 1982. The life cycle of the green crab Carcinus maenas at the northern end of its range. Journal of Crustacean Biology 2:31-39. 
825 Bertness MD, Gaines SD, Stephens EG, Yund PO. 1992. Components of recruitment in

826

827

828

829

830

831

832

833

834

835

836

837

838

839

840

841

842

843

844

845

846

847

populations of the acorn barnacle Semibalanus balanoides (Linnaeus). Journal of Experimental Marine Biology and Ecology 156:199-215.

Bertness MD, Gaines SD, Wahle RA. 1996. Wind-driven settlement patterns in the acorn barnacle Semibalanus balanoides. Marine Ecology Progress Series 137:103-110.

Boudreau MR, Hamilton DJ. 2012. Seasonal variation in effects of multiple predators on an intertidal mussel bed: implications for interpretation of manipulative experiments. Marine Ecology Progress Series 465:137-153.

Byrne M. 2011. Impact of ocean warming and ocean acidification on marine invertebrate life history stages: vulnerabilities and potential for persistence in a changing ocean. Oceanography and Marine Biology: An Annual Review 49:1-42.

Casey KS, Brandon TB, Cornillon P, Evans R. 2010. The past, present and future of the AVHRR Pathfinder SST Program. In: Barale V, Gower JFR, Alberotanza L, eds. Oceanography from Space: Revisited. Netherlands: Springer, 273-287. DOI: 10.1007/978-90-481-86815_16.

Clements JC. 2016. Influence of sediment acidification on the burrowing behaviour, postsettlement dispersal, and recruitment of juvenile soft-shell clams (Mya arenaria L.). D. Phil. Thesis, University of New Brunswick, Saint John, NB.

Cohen P, West SG, Aiken LS. 2003. Applied Multiple Regression/Correlation Analysis for the Behavioral Sciences (3 ${ }^{\text {rd }}$ Edition). Mahwah, NJ: Lawrence Earlbaum Associates.

Copping A, Sather N, Hanna L, Whiting J, Zydlewski G, Staines G, Gill A, Hutchison I, O’Hagan A, Simas T, Bald J, Sparling C, Wood J, Masden E. 2016. Annex IV 2016 State of the Science Report: Environmental Effects of Marine Renewable Energy Development 
848

849

850

851

852

853

854

855

856

857

858

859

860

861

862

863

864

865

866

867

868

869

Around the World. Available at https://tethys.pnnl.gov/publications/state-of-the-science$\underline{2016}$ (accessed 1 June 2017).

Cosham JA, Beazley KF, McCarthy C. 2016. Local knowledge of distribution of European green crab (Carcinus maenas) in southern Nova Scotian coastal waters. Human Ecology 44:409-424. DOI: 10.1007/s 10745-016-9825-x.

Crothers JH. 1967. The biology of the shore crab, Carcinus maenas (L.). 1. The backgroundanatomy, growth and life history. Field Studies 2:407-434.

Crothers JH. 1968. The biology of the shore crab, Carcinus maenas (L.). 2. The life of the adult crab. Field Studies 2:579-614.

Daborn GR, Pennachetti C. 1979. Zooplankton studies in the southern bight of Minas Basin. Proceedings of the Nova Scotian Institute of Science 29:465-481.

Dawirs RR. 1985. Temperature and larval development of Carcinus maenas (Decapoda) in the laboratory; predictions of larval dynamics in the sea. Marine Ecology Progress Series 24:297-302.

Elner RW, Hughes RN. 1978. Energy maximization in the diet of the shore crab Carcinus maenas. Journal of Animal Ecology 47:103-116.

Fisheries and Oceans Canada. 2018. Bedford Institute of Oceanography. The Sea-surface Temperature (SST) Database. Available at http://dfnsb2ywvwsp001.dfo-

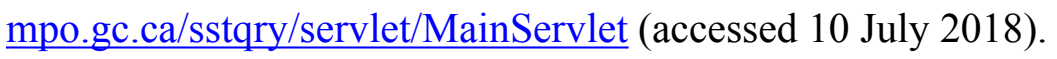

Government of Canada. 2018. Historical Climate Data, Daily Data Report: Parrsboro, Nova Scotia. Available at http://climate.weather.gc.ca/index_e.html (accessed 15 February 2018). 
870 Grafen A, Hails R. 2002. Modern Statistics for the Life Sciences. Oxford, UK: Oxford University $871 \quad$ Press.

872 Grosholz E, Ruiz GM, Dean CA, Shirely KA, Maron JL, Connnors PG. 2000. The impacts of a 873 nonindigenous marine predator in a California bay. Ecology 81:1206-1224.

874 Haarr ML, Rochette R. 2012. The effect of geographic origin on interactions between adult 875 invasive green crabs carcinus maenas and juvenile American lobsters Homarus americanus in Atlantic Canada. Journal of Experimental Marine Biology and Ecology 422-423:88-100.

878

879

880

881

882

883

884 885

886

887

888

889

890

891

892

Hetzel Y, Pattriaratchi C, Lowe R, Hofmeister R. 2015. Wind and tidal mixing controls on stratification and dense water outflows in a large hypersaline bay. Journal of Geophysical Research: Oceans 120:6034-6056.

Hoskin MG, Coleman RA, von Carlshausen E, Davis CM. 2011. Variable population responses by large decapod crustaceans to the establishment of a temperate marine no-take zone. Canadian Journal of Fisheries and Aquatic Sciences 68:185-200.

Hunter E, Naylor E. 1993. Intertidal migration by the shore crab Carcinus maenas. Marine Ecology Progress Series 101:131-138.

Huntingford FA, Taylor AC. 1997. The influence of resource value on the agonistic behaviour of the shore crab, Carcinus maenas (L.). Marine and Freshwater Behaviour and Physiology 30:225-237.

Hurrell JW, Kushnir Y, Ottersen G, Visbeck M. 2003. An overview of the North Atlantic Oscillation. In: Hurrell JW, Kushnir Y, Ottersen G, Visbeck M, eds. The North Atlantic Oscillation: Climatic Significance and Environmental Impact (Geophysical Monograph 134). Washington, DC: The American Geophysical Union, 1-35. 
893 International Research Institute for Climate and Society. 2018. Earth Institute, Columbia

$894 \quad$ University. Monthly Sea Surface Temperature. Available at

895 https://iridl.ldeo.columbia.edu/maproom/Global/Ocean_Temp/Monthly_Temp.html

$896 \quad$ (accessed 12 July 2018).

897 Jury SH, Howell WH, Watson WH, III. 1995. Lobster movement in response to a hurricane.

898 Marine Ecology Progress Series 119:305-310.

899 Kent CPS, McGuinness. 2006, A comparison of methods for estimating relative abundance of

$900 \quad$ grapsid crabs. Wetlands Ecology and Management 14:1-9.

901 Kienzle H. 2015. Population dynamics and interactions between invasive green crabs (Carcinus

902 maenas) and native rock crabs (Cancer irroratus) in intertidal zones of the upper Bay of

903 Fundy. B.Sc. (Hon.) Thesis, Mount Allison University, Sackville, NB.

904

Klassen G, Locke A. 2007. A biological synopsis of the European green crab, Carcinus maenas. Canadian Manuscript Report of Fisheries and Aquatic Sciences 2818:1-75.KleinMacPhee G. 2002. Sculpins. Family Cottidae. In: Collette BB, Klein-MacPhee G, eds. Bigelow and Schroeder's Fishes of the Gulf of Maine ( $3^{\text {rd }}$ Edition). Washington, DC: Smithsonian Institution Press, 346-357.

MacDonald AJ, Kienzle HM, Drolet D, Hamilton DJ. 2018. Distribution and habitat use of the invasive Carcinus maenas L. (European green crab) and the native Cancer irroratus (Say) (rock crab) in intertidal zones in the upper Bay of Fundy, Canada. Northeastern Naturalist 25:161-180.

McGaw IJ, Edgell TC, Kaiser MJ. 2011. Population demographics of native and newly invasive populations of the green crab Carcinus maenas. Marine Ecology Progress Series 430:235-240. 
916 McGaw IJ, Reiber CL, Guadagnoli JA. 1999. Behavioral physiology of four crab species in low $917 \quad$ salinity. Biological Bulletin 196:163-176.

918 Meehl GA, Zwiers F, Evans J, Knutson T, Mearns L, Whetton P. 2000. Trends in extreme

919

920

921

922

923

924

925

926

927

928

929

930

931

932

933

934

935

936

937

938 weather and climate events: issues related to modeling extremes in projections of future climate change. Bulletin of the American Meteorological Society 81:427-436.

Mills KE, Pershing AJ, Brown CJ, Chen Y, Chiang F-S, Holland DS, Lehuta S, Nye JA, Sun JC, Thomas AC, Wahle RA. 2013. Fisheries management in a changing climate: lessons from the 2012 ocean heat wave in the Northwest Atlantic. Oceanography 26:191-195.

Miller RJ. 2009. History, assessment methods, and regulation of Nova Scotia's bloodworm Glycera dibranchiata) harvest. DFO Canadian Science Advisory Secretariat Research Document 2009/064:1-32.

Miller JJ, Maher M, Bohaboy E, Friedman CS, McElhany P. 2016. Exposure to low pH reduces survival and delays development in early life stages of Dungeness crab (Cancer magister). Marine Biology 163:118. DOI:10.1007/s00227-016-2883-1.

Miralto A, Barone G, Ramano G, Poulet SA, Ianora A, Russo GL, Buttino I, Mazzarella G, Laabir M, Cabrini M, Giacobbe MG. 1999. The insidious effect of diatoms on copepod reproduction. Nature 402:173-176.

Moksnes P-O, Corell H, Tryman K, Hordoir R, Jonsson PR. 2014. Larval behavior and dispersal mechanisms in shore crab larvae (Carcinus maenas): local adaptations to different tidal environments? Limnology and Oceanography 59:588-602.

Moore AM, Vercaemer B, DiBacco C, Sephton D, Ma KCK. 2014. Invading Nova Scotia: first records of Didemnum vexillum Kott, 2002 and four more non-indigenous invertebrates in 2012 and 2013. BioInvasions Records 3:225-234. 
939 Munroe, TA. 2002. Wrasses. Family Labridae. In: Collette BB, Klein-MacPhee G, eds. Bigelow 940 and Schroeder's Fishes of the Gulf of Maine ( $3^{\text {rd }}$ Edition). Washington, DC: Smithsonian $941 \quad$ Institution Press, 448-466.

942 Nagaraj M. 1993. Combined effects of temperature and salinity on the zoeal development of the green crab, Carcinus maenas (Linnaeus, 1758) (Decapoda: Portunidae). Scientia Marina 57:1-8.

945

National Center for Atmospheric Research Staff. 2018. The Climate Data Guide: Hurrell North Atlantic Oscillation (NAO) Index (PC-Based). Available at https://climatedataguide.ucar.edu/climate-data/hurrell-north-atlantic-oscillation-naoindex-pc-based (accessed 15 February 2018).

Niehaus AC, Angilletta MJ, Jr., Sears MW, Franklin CE, Wilson RS. 2012. Predicting the physiological performance of ectotherms in fluctuating thermal environments. Journal of Experimental Biology 215:694-701.

Palumbi SR, Pinsky ML. 2014. Marine dispersal, ecology, and conservation. In: Bertness MD, Bruno JF, Silliman BR, Stachowicz JJ, eds. Marine Community Ecology and Conservation. Sinauer: Sunderland, 57-83.

Parker M, Westhead M, Service A. 2007. Ecosystem Overview Report for the Minas Basin, Nova Scotia. DFO Oceans and Coastal Management Report 2007-05:1-179.

Petrie B. 2007. Does the North Atlantic Oscillation affect hydrographic properties of the Canadian Atlantic continental shelf? Atmosphere-Ocean 43:141-151. DOI: 10.3137/ao.450302.

Pinksy ML, Worn B, Fogarty MJ, Samiento JL, Levin SA. 2013. Marine taxa track local climate velocities. Science 341:1239-1242. 
962 Quinn BK. 2016. Identification of Phymatolithon lamii (Me. Lemoine) Y .M. Chamberlain 1991

963 following bleaching in the upper intertidal zone of the Minas Basin, Nova Scotia,

964 Canada. Journal of Coastal Life Medicine 4:181-186.

965 Quinn BK, Chassé J, Rochette R. 2017. Potential connectivity among American lobster fisheries

966 as a result of larval drift across the species' range in eastern North America. Canadian

967 Journal of Fisheries and Aquatic Sciences 74:1549-1563. DOI: 10.1139/cjfas-2016-0416.

968

969

970

971

972

973

974

975

976

977

978

979

980

981

982

983

984

Reynolds RW, Rayner NA, Smith TM, Stokes DC, Wang W. 2002. An improved in situ and satellite SST analysis for climate. Journal of Climate 15:1609-1625.

Ruth M, Berghahn R. 1989. Biological monitoring of fish and crustaceans in the Wadden Seapotential and problems. Helgoländer Meeresuntersuchungen 43:479-487.

Santos SL, Simon JL. 1980. Marine soft-bottom community establishment following annual defaunation: larval or adult recruitment? Marine Ecology Progress Series 2:235-241.

Sato S, Chiba T. 2016. Structural changes in molluscan community over a 15-year period before and after the 2011 Great East Japan Earthquake and subsequent tsunami around Matsushima Bay, Miyagi Prefecture, northeastern Japan. PLoS ONE 11:e0168206. DOI: 10.1371/journal.pone.0168206.

Scalici M, Gherardi F. 2007. Structure and dynamics of an invasive population of the red swamp crayfish (Procambarus clarkii) in a Mediterranean wetland. Hydrobiologia 583:309-319.

Scrosati RA, Ellrich JA. 2016. A 12-year record of intertidal barnacle recruitment in Atlantic Canada (2005-2016): relationships with sea surface temperature and phytoplankton abundance. PeerJ 4:e2623. DOI: 10.7717/peerj.2623.

Scrosati RA, Ellrich JA. 2018. Thermal moderation of the intertidal zone by seaweed canopies in winter. Marine Biology 165:115. DOI: 10.1007/s00227-018-3374-3. 
985 Scrosati RA, Grant JL, Brewster JD. 2012. Density and size gradients across species distribution 986 ranges: testing predictions from the abundant-centre model using the vertical distribution

987

988

989

990

991

992

993

994

995

996

997

998

999

1000

1001

1002

1003

1004

1005 of intertidal barnacles. Vie et Milieu - Life and Environment 62:197-202.

Seitz RD, Knick KE, Westphal M. 2011. Diet selectivity of juvenile blue crabs (Callinectes sapidus) in Chesapeake Bay. Integrative and Comparative Biology 51:598-607.

Somers KM. 1991. Characterizing size-specific fecundity in crustaceans. In: Wenner A, Kuris A, eds. Crustacean Issues 7: Crustacean Egg Production. Rotterdam, the Netherlands: A.A. Balkema, 357-378.

Soper DS. 2017. p-Value Calculator for Correlation Coefficients. Available at: http://www.danielsoper.com/statcalc (accessed 1 May 2018).

Trussell GC, Ewanchuck PJ, Bertness MD. 2003. Trait-mediated effects in rocky intertidal food chains: predator risk cues alter prey feeding rates. Ecology 84:629-640.

Wahle R, Carloni J. 2017. American Lobster Settlement Index - Update 2016. Available at http://umaine.edu/wahlelab/american-lobster-settlement-index-alsi/american-lobster-

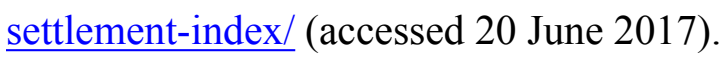

Wessel P, Smith WHF, Scharroo R, Luis J, Wobbe F. 2013. Generic Mapping Tools: improved version released. Eos, Transactions American Geophysical Union 94: 409-410.

Wilson WH, Jr., Ruff RE. 1988. Species profiles: life histories and environmental requirements of coastal fishes and invertebrates (North Atlantic) - sandworm and bloodworm. U.S. Fish and Wildlife Service Biological Report 82(11.80). U.S. Army Corps of Engineers, TR EL-82-4:1-23. 
1006 Wong MC, Dowd M. 2015. Role of invasive green carbs in the food web of an intertidal sand flat determined from field observations and a dynamic simulation model. Estuaries and Coasts 37:1004-1016.

1009 Woodard K. 2018. Investigating the role of temperature-mediated embryo development in the range expansion of cunner into the Bay of Fundy, Canada. M.Sc. Thesis, University of New Brunswick, Saint John, NB.

1012 


\section{Table $\mathbf{1}$ (on next page)}

Sampling effort during intertidal and subtidal green crab monitoring at Clarke Head, NS in different years and months.

Columns for intertidal crab sampling in June-September list the number of sampling trips made per each month. Quadrats used measured $1 \mathrm{~m}^{2}$. 


\begin{tabular}{|c|c|c|c|c|c|c|c|c|}
\hline \multirow[t]{4}{*}{ Year } & \multicolumn{6}{|c|}{ Intertidal crab sampling } & \multicolumn{2}{|c|}{ Subtidal crab bycatch } \\
\hline & June & July & August & Sentember & Total \# & Total \# & Total \# & Total \# \\
\hline & & & & & quadrats & crabs & fishing & crabs \\
\hline & & & & & sampled & found & trips & caught \\
\hline 2008 & 1 & 2 & 2 & 1 & 140 & 394 & 8 & 35 \\
\hline 2009 & 2 & 3 & 3 & 3 & 220 & 896 & 5 & 18 \\
\hline 2010 & 1 & 1 & 1 & 1 & 80 & 641 & 10 & 39 \\
\hline 2011 & 1 & 0 & 0 & 1 & 40 & 198 & 8 & 29 \\
\hline 2012 & 0 & 2 & 3 & 2 & 140 & 1232 & 6 & 32 \\
\hline 2013 & 1 & 5 & 6 & 3 & 320 & 86 & 9 & 1 \\
\hline 2014 & 3 & 4 & 4 & 2 & 240 & 112 & 5 & 3 \\
\hline 2015 & 1 & 2 & 1 & 1 & 80 & 168 & 4 & 7 \\
\hline 2016 & 0 & 1 & 0 & 1 & 30 & 103 & 1 & 2 \\
\hline 2017 & 0 & 1 & 2 & 0 & 88 & 210 & 3 & 8 \\
\hline
\end{tabular}

2 


\section{Table 2 (on next page)}

Correlations between biological characters of thecrab population in each sampled year and average observed intertidal crabdensities.

Values presented in the table are Pearson's correlation coefficients ( $r$ ). Significant correlations $(r<-0.630$ or $r>+0.630, N=10, p \leq 0.05$; Cohen, West, \& Aiken, 2003; Soper, 2017) are indicated by bold text and asterisks as follows: *, $0.01<p \leq 0.05 ; * *, 0.001<p \leq$ $0.01 ; * *, p<0.001$. 
1

\begin{tabular}{llc}
\hline Predictor variable type & & Correlation \\
\hline Proportion of crabs & Mature & $\mathbf{+ 0 . 4 8 6 * * *}$ \\
& Female & $+\mathbf{0 . 4 0 7 * * *}$ \\
& Ovigerous & $\mathbf{- 0 . 5 0 6 * * *}$ \\
\hline Mean size (mm CW) & All crabs & $\mathbf{+ 0 . 5 4 4 * * *}$ \\
& Female (all) & $\mathbf{+ 0 . 4 9 9 * * *}$ \\
& Ovigerous female & $\mathbf{+ 0 . 5 4 9 * * *}$ \\
& Female (non-ovigerous) & $\mathbf{+ 0 . 3 7 3 * *}$ \\
\hline Number juvenile crabs observed & Total & $+\mathbf{0 . 5 2 8 * * *}$ \\
\hline
\end{tabular}

2 


\section{Table 3 (on next page)}

Results of stepwise multiple regressions done to find the best combination of environmental variables to explaininterannual changes in intertidal green crab densities at Clarke Head, NS from2008-2017.

One of each type of environmental predictors [air temperature (AirTemp), sea-surface temperature (SST), precipitation (Precip), wind direction (WindDir), wind speed (WindSpeed), North Atlantic Oscillation index (NAOI), and potential settlement (AnnSettlement)] that had the strongest, significant correlation with intertidal density was used in these analyses (see Fig. 6A-L). The average (Mean), standard deviation (SD), minimum (Min), and maximum (Max) daily values of predictor variables in different months (Jan-Dec) of the previous year (PY) and same year (SY) as densities were sampled were tested. The variables in each model in bold text were significant in the regression models used $(p \leq 0.05)$. Progressively simpler models were tested, going from a 'full' model containing all seven potential predictors (model \#1) to models (\#2-6) with fewer variables, removing the non-significant predictor with the highest p-value at each step until only significant predictors remained (\#6). An intercept-only ('null') model (\#0) was also tested for comparison with other models. Also calculated to assess fit and select the best model were $r^{2}$ (fit), $\mathrm{AlC}_{\mathrm{c}}$ values (fit penalized based on the number of parameters, $k$, in a given model), $\Delta_{i}$, and AIC weight $\left(w_{i}\right)$ values (see Methods text and Anderson 2008, for details); models were ranked based on $\mathrm{AlC}_{c}$ values. 


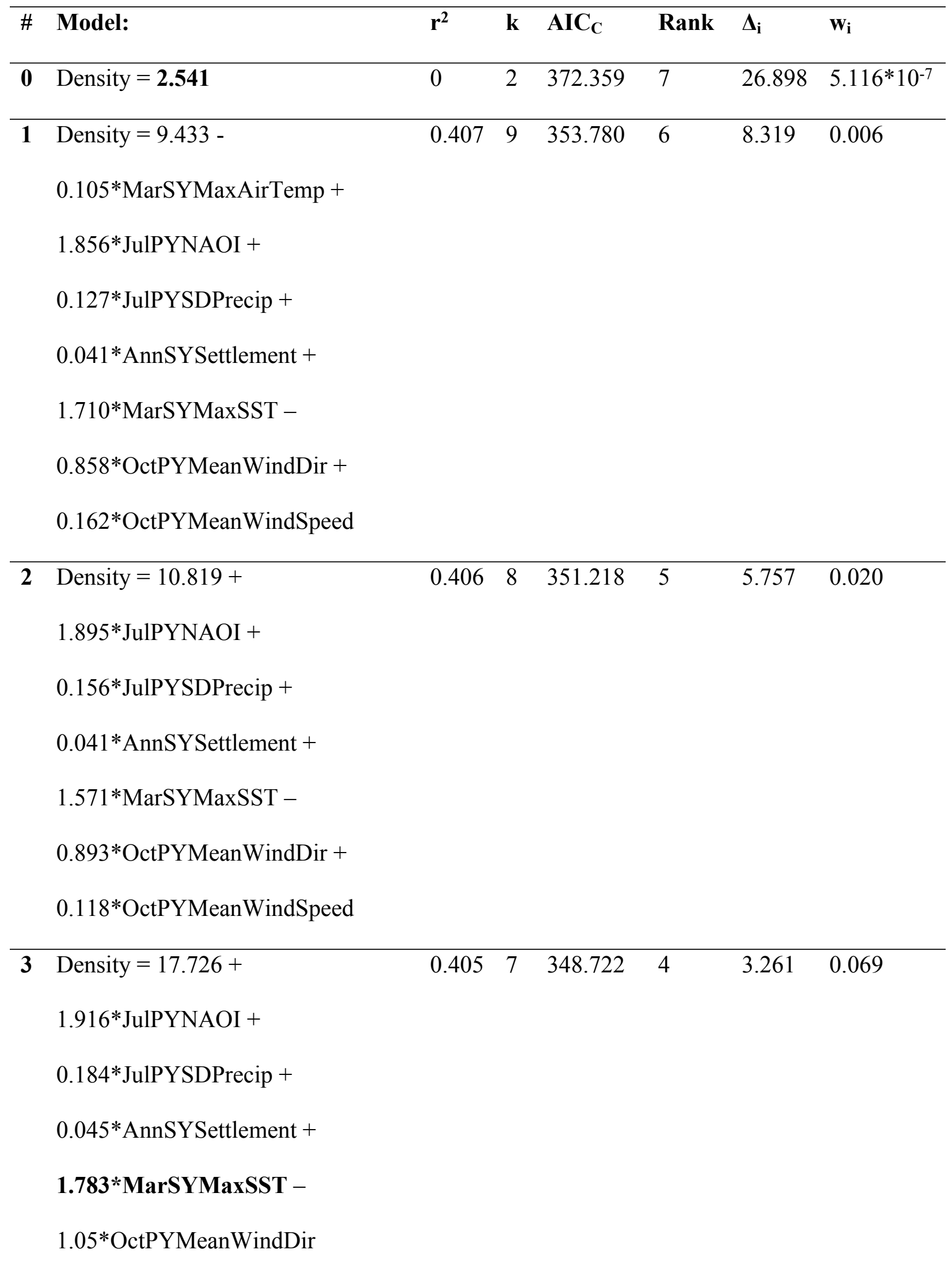




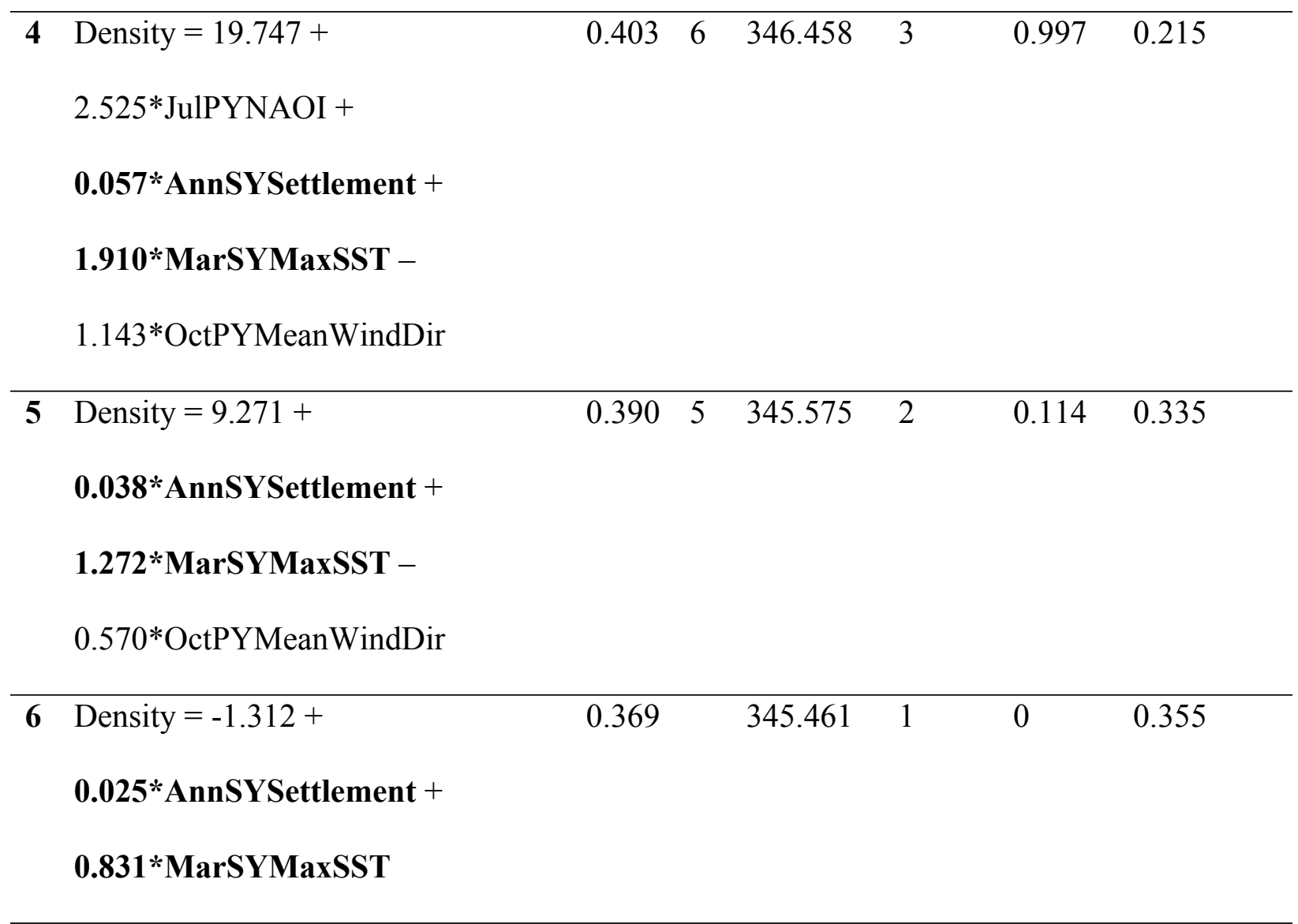

1 


\section{Figure 1}

Map, features, and location of the study site at Clarke Head, Nova Scotia (NS).

(A) Photograph of an adult male green crab (Carcinus maenas) examined at the study site.

(B) Photograph of the study site, taken toward the shore from the low tide mark from the approximate location of the red dot in (C); reefs surveyed for crabs are visible mainly on the right and left sides of the image. (C) Map showing details of the study site, including bottom substrate types on the intertidal zone; solid gray area is land, white areas are subtidal, black areas are rockweed reefs where crabs were sampled in this study, asterisk is the location of a previous study (Quinn, 2016). (D) Map showing the location of the study site (red square) and Minas Basin (rectangular outline) within Atlantic Canada. Photographs in (A) and (B) were both taken by the author in July 2015, and both maps were made by the author (C) by hand or (D) using Generic Mapping Tools GMT-5.3.1 (Wessel et al. 2013; available online from http://gmt.soest.hawaii.edu/ ). 

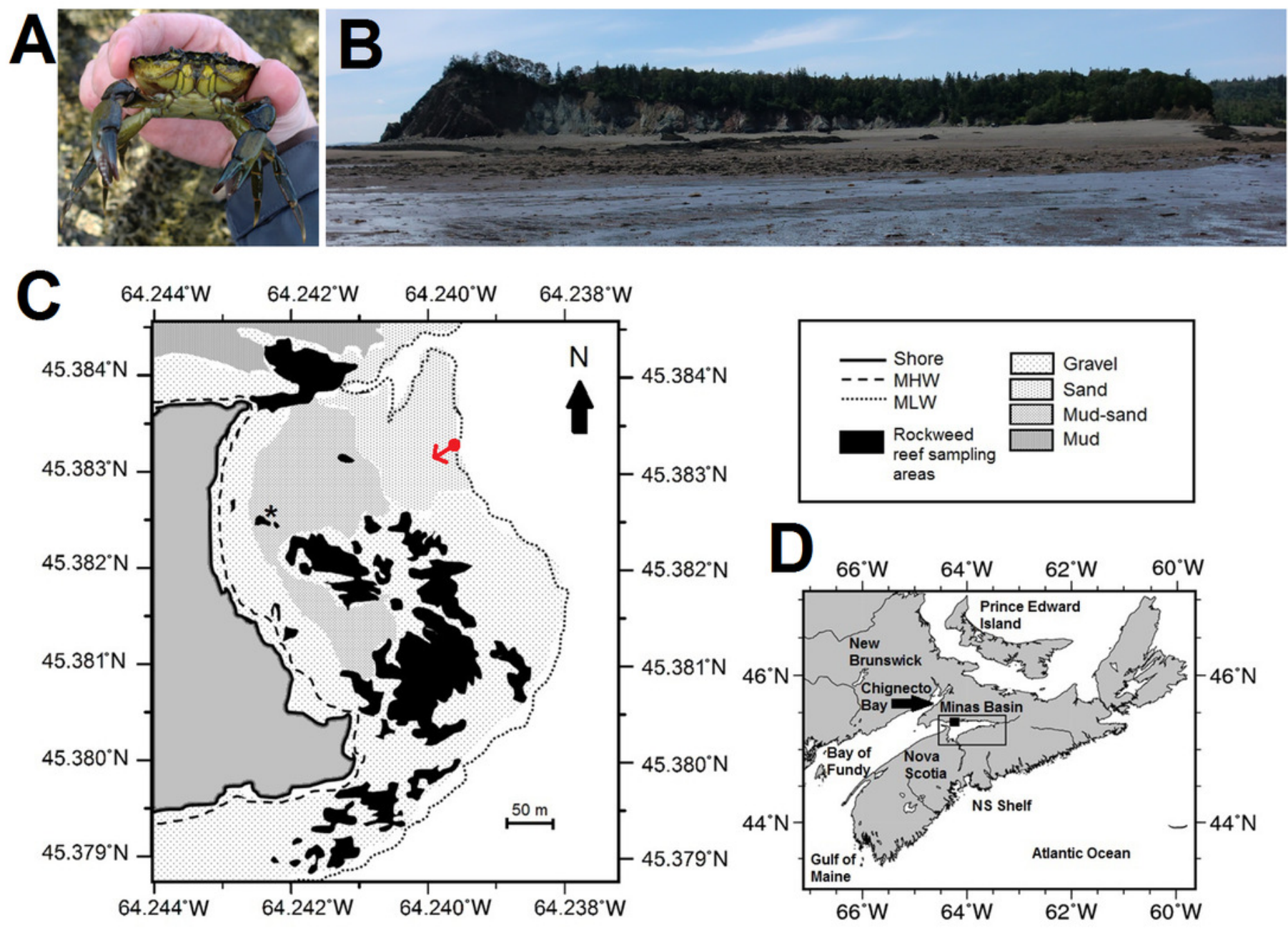
Figure 2

Average \pm standard error (SE) annual intertidal densities (individuals per $\mathrm{m} 2$ ) of green crabs in the Clarke Head population in different years from 2008 to 2017.

The solid horizontal and dashed lines are the overall mean $\pm 95 \%$ confidence intervals (C.I.S) of intertidal density from 2008-2017. Different letters above yearly means indicate years with significantly different crab abundances (Tukey's HSD test, $p \leq 0.05$ ). Asterisks ('*’) indicate years in which crab abundance was significantly different (i.e. greater) than that observed in 2013 (Dunnet's pairwise multiple comparison t-test, $p \leq 0.05$ ).

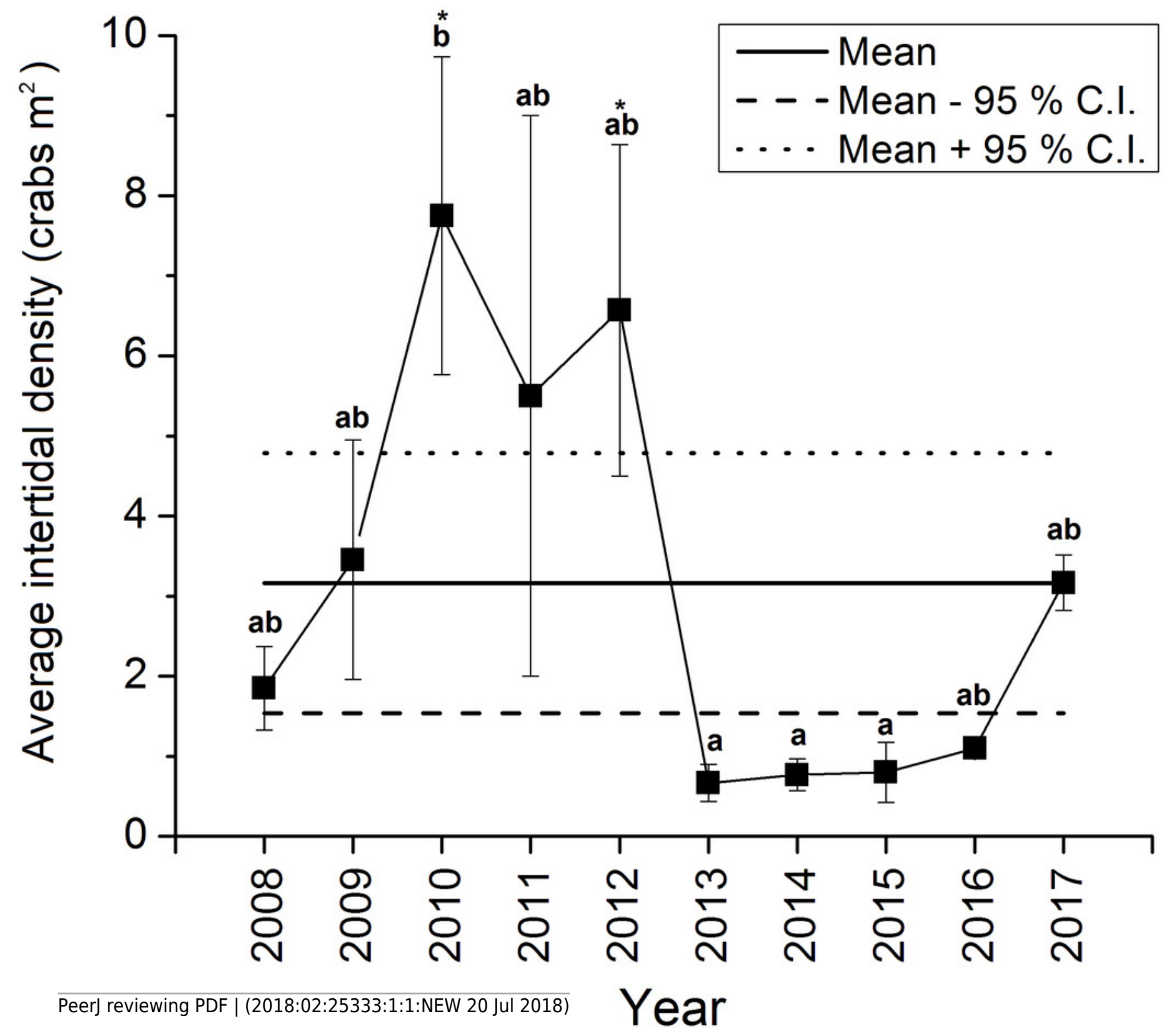


Figure 3

Detailed size structure of green crabs observed on the intertidal at Clarke Head, NS in each year monitored (2008-2017).

Each plot shows the proportion (y-axes) of all crabs observed in each year from (A) 2008 to (J) 2017 (summed across all sampling trips) that fell within each $5 \mathrm{~mm}$ carapace width (CW) size bin (x-axes). Differently coloured bars indicate juvenile (black), ovigerous female (OV, blue), non-ovigerous female (NO, red), and male (green) crabs. All bars in each yearly plot should sum to 1.0 .

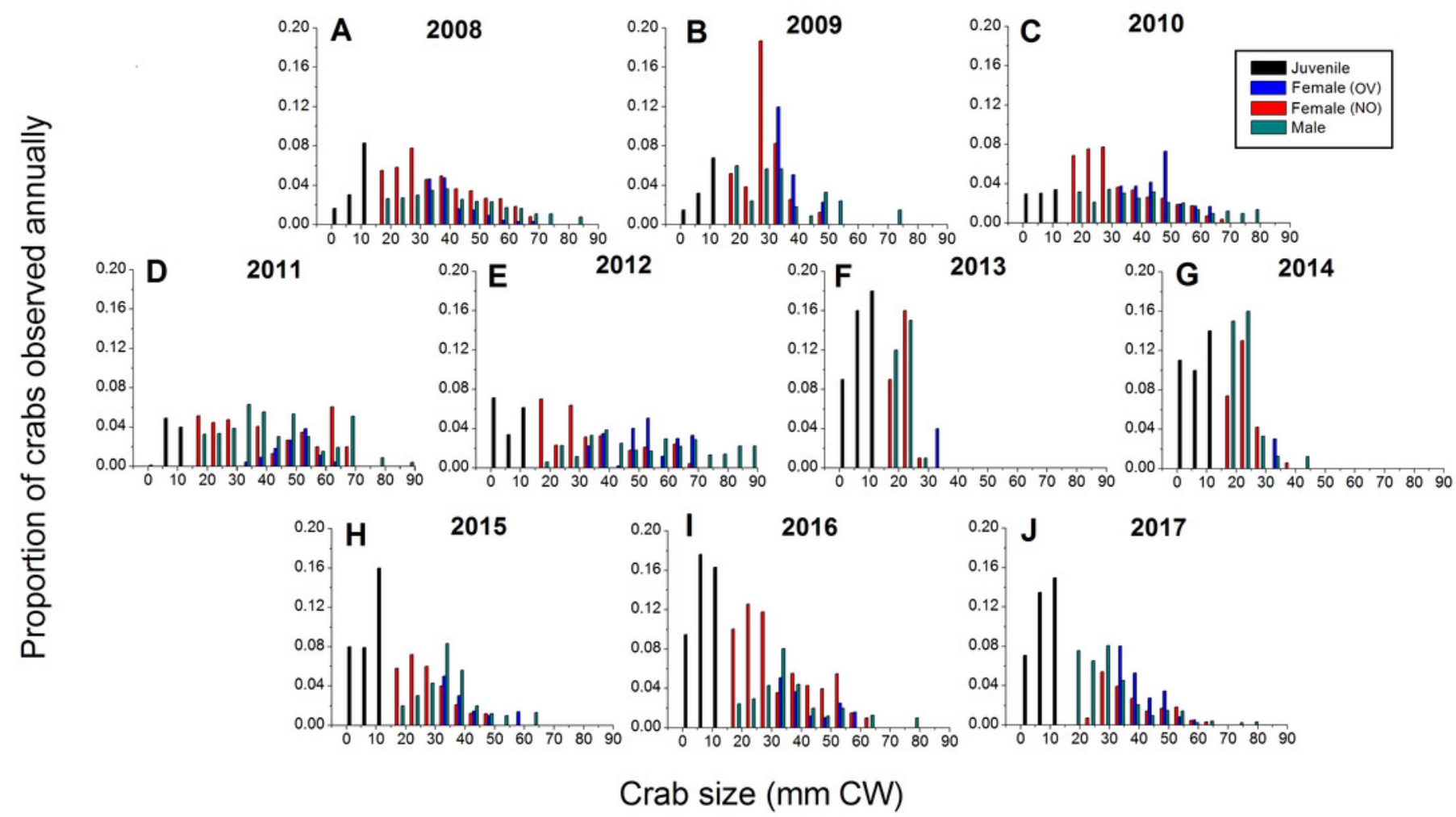




\section{Figure 4}

Demographic characteristics (proportions in different reproductive categories or sizes) of the green crab population at Clarke Head, NS in each monitored year.

Plots show: (A) the proportion of all crabs observed in each year (summed across all sampling trips) that were mature ( $\mathrm{CW} \geq 15 \mathrm{~mm}$; black squares), the proportion of all mature crabs that were female (red circles), and the proportion of all female crabs that were ovigerous (blue triangles); (B) the mean $\pm \mathrm{SE}$ size ( $\mathrm{mm} \mathrm{CW}$ ) of all crabs in each year overall or fit into different categories (represented by different symbol types). 

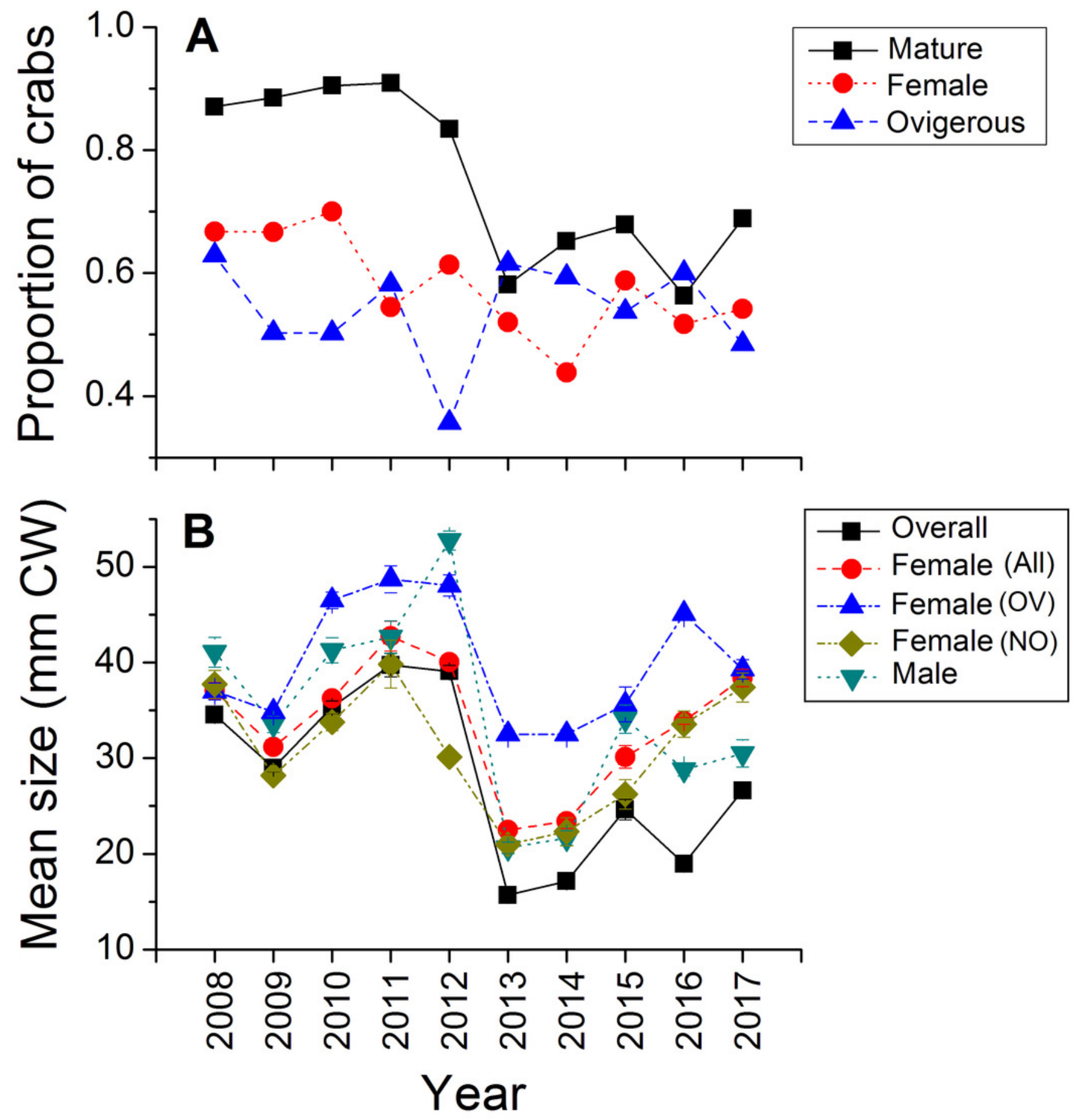


\section{Figure 5}

Abundance of juvenile and large subtidal crabs in the monitored green crab population at Clarke Head in different years from 2008-2017.

Plots show: (A) Total annual observed numbers of juvenile ( $\mathrm{CW} \leq 15 \mathrm{~mm}$ ) crabs (black squares) and model-predicted numbers of settling crab larvae (1000s of megalopae; gray circles); and (B) catch-per-unit-effort (CPUE) of large crabs in the subtidal zone (number of crabs caught as bycatch per fishing trip by recreational fishers). In (B) the solid and dashed horizontal lines represent the overall mean $\pm 95 \%$ confidence intervals (C.I.) of subtidal CPUE across all years. 

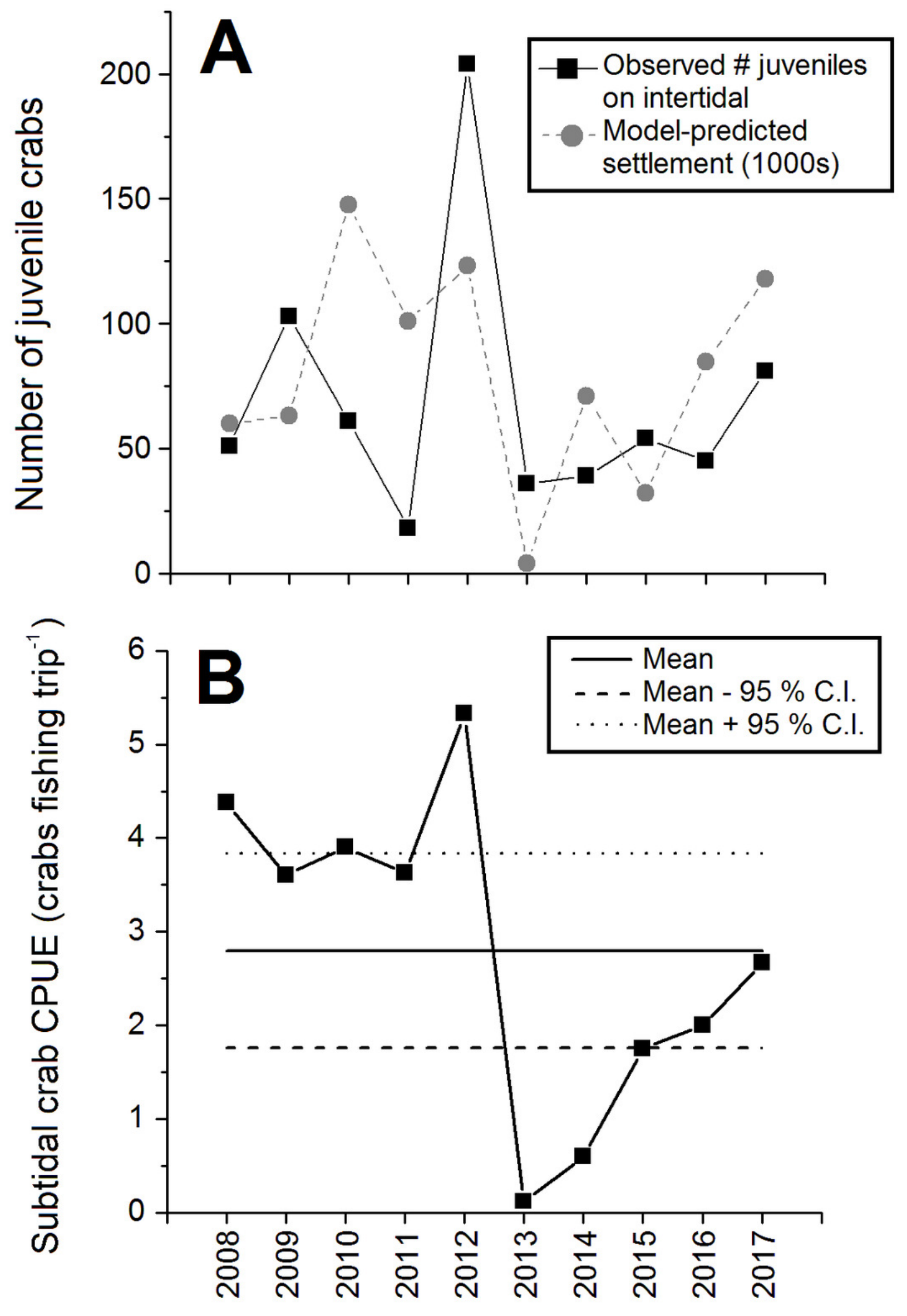


\section{Figure 6}

Environmental variables most strongly correlated to intertidal densities across years.

The values of the potential environmental predictor variables (left $y$-axes and black squares) examined in each year ( $\mathrm{x}$-axes) that resulted in the 1st (A) to 12th (K) strongest correlations with average annual intertidal crab densities (right $y$-axes, gray squares) of those tested (see Supplementary Materials for all correlations). The 6th strongest correlation of all was found for total predicted settlement in each year (see Fig. 5A and Results text). The NAO index variable with the strongest observed correlation to intertidal density (36th highest r-value) is also shown (L). For details and sources of data, see the Methods text. The average (Mean), standard deviation (SD), minimum (Min), and maximum (Max) daily values of predictor variables in different months (Jan-Dec) of the previous year (PY) and same year (SY) as densities were sampled were tested. These included air temperature (AirTemp), sea-surface temperature (SST), precipitation (Precip), wind direction (WindDir), wind speed (WindSpeed), North Atlantic Oscillation index (NAOI), and potential settlement (AnnSettlement). Significant correlations $(r<-0.630$ or $r>+0.630, N=10, p \leq 0.05$; Cohen, West, \& Aiken, 2003; Soper, 2017) are indicated by bold text and asterisks as follows: *, $0.01<p \leq 0.05 ; * *, 0.001<p \leq$ $0.01 ; * * *, p<0.001$. 
A MarSYMaxSST

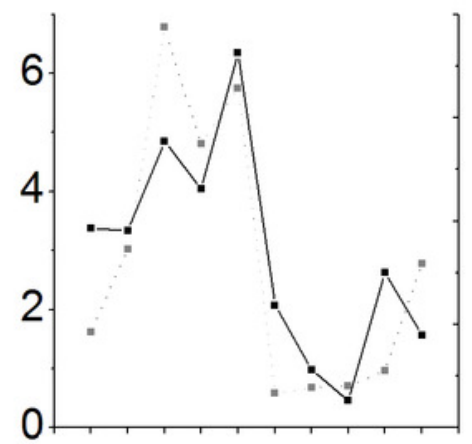

D $\begin{aligned} & \text { OctPYMeanW } \\ & r=+0.531^{\star * *}\end{aligned}$

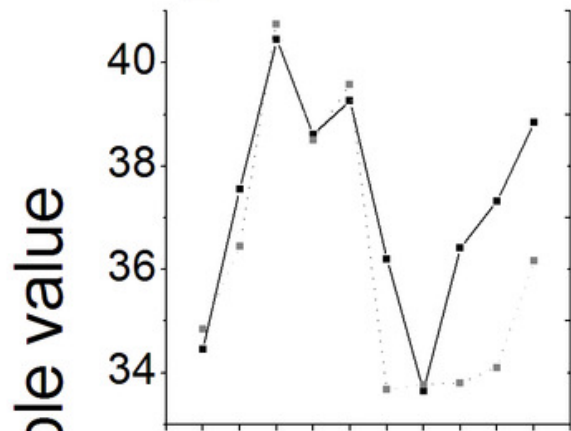

0

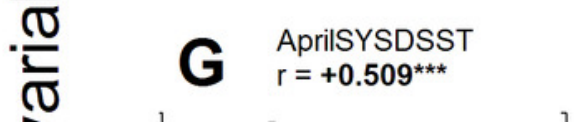

$>$

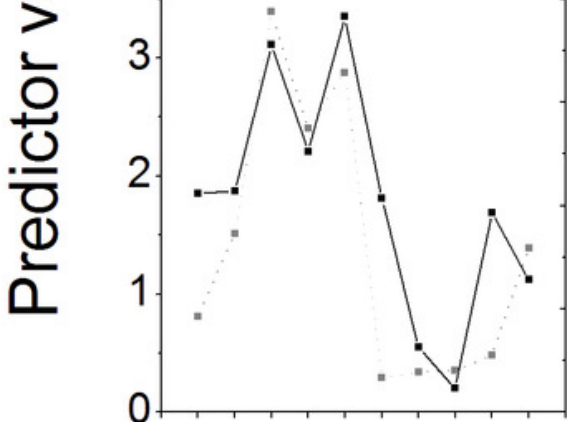

I AprSYMinSST

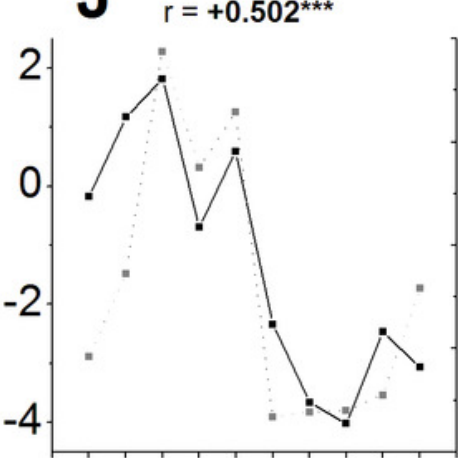

món-Nmthen

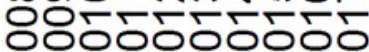
กักำกำกำ
B $\begin{aligned} & \text { AprilSYMaxSST } \\ & \mathrm{r}=+0.547^{\star \star *}\end{aligned}$

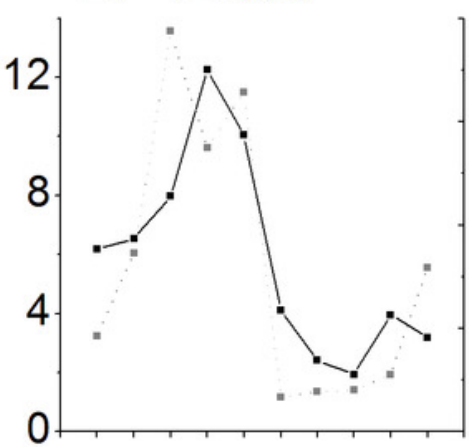

E $\begin{aligned} & \text { MarSYMinSST } \\ & r=+0.527^{\star \star \star}\end{aligned}$

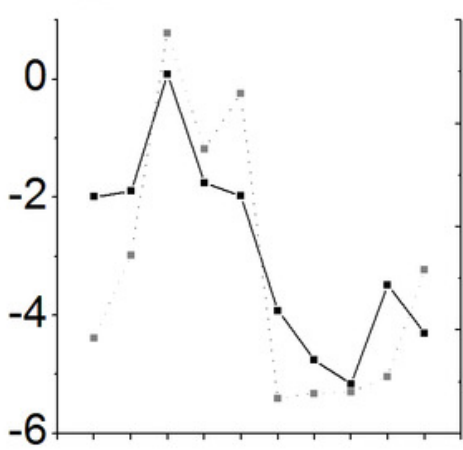

H MarSYMaxAirTemp

20

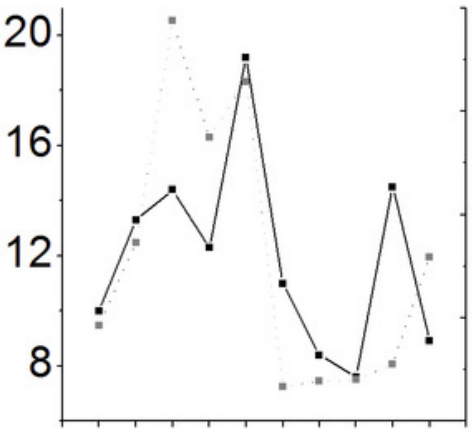

K OctPYMeanWindDir

30

K $\begin{aligned} & \text { OctPYMeanW } \\ & r=+0.500^{\star * *}\end{aligned}$

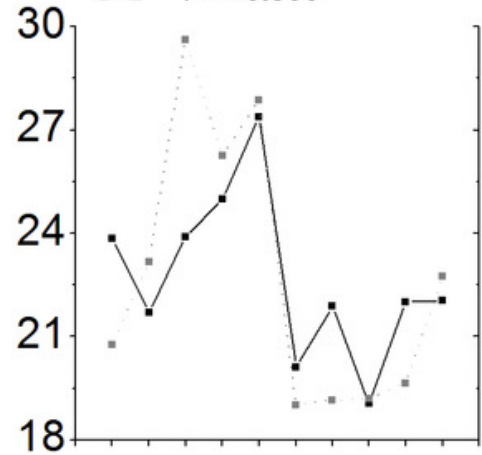

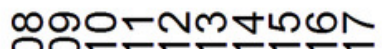

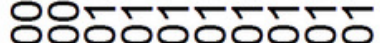

ำกำำกำ

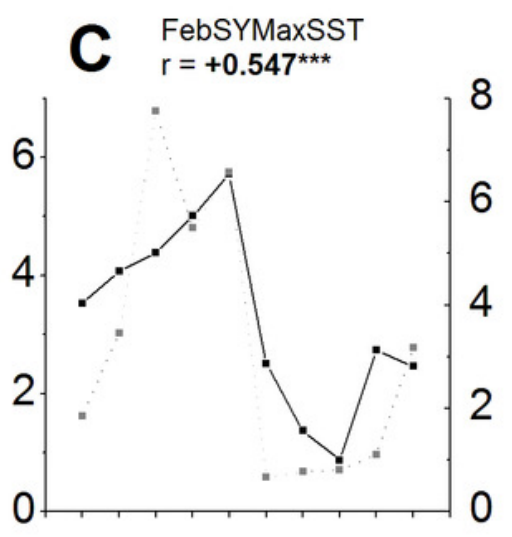

F $\begin{aligned} & \text { AprSYMeanSST } \\ & r=+0.509^{\star \star \star}\end{aligned}$

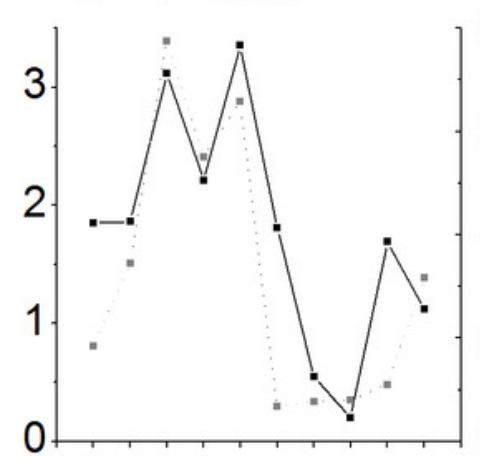

8

6

$\frac{1}{2}$
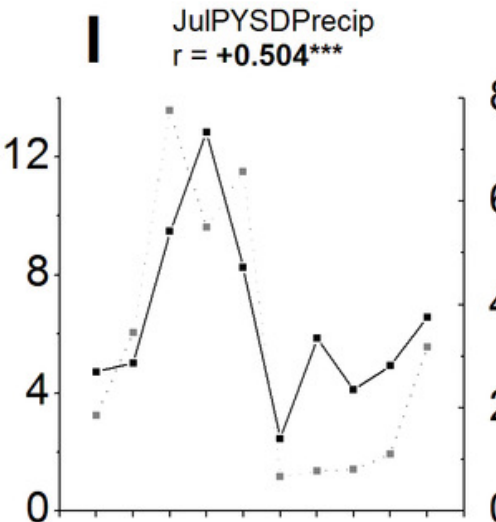

8

4 ค

2 0

3

í

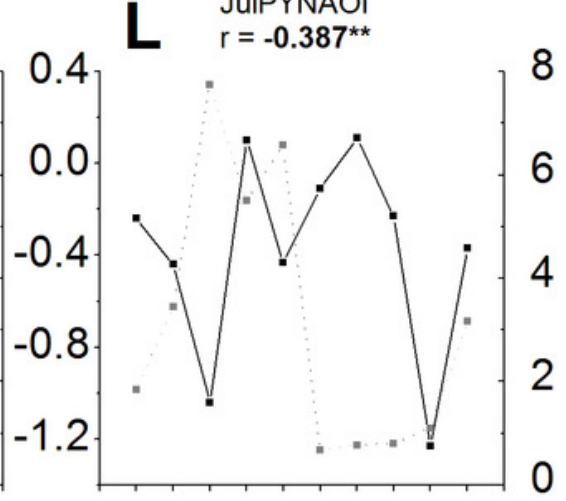

mornm

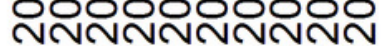

